University of Louisville

ThinkIR: The University of Louisville's Institutional Repository

Electronic Theses and Dissertations

$12-2018$

\title{
Influences of porphyromonas gingivalis on the viability of esophageal cancer cells.
}

\author{
Muddasir Mohammed \\ University of Louisville
}

Follow this and additional works at: https://ir.library.louisville.edu/etd

Part of the Oral Biology and Oral Pathology Commons

\section{Recommended Citation}

Mohammed, Muddasir, "Influences of porphyromonas gingivalis on the viability of esophageal cancer cells." (2018). Electronic Theses and Dissertations. Paper 3101.

https://doi.org/10.18297/etd/3101

This Master's Thesis is brought to you for free and open access by ThinkIR: The University of Louisville's Institutional Repository. It has been accepted for inclusion in Electronic Theses and Dissertations by an authorized administrator of ThinkIR: The University of Louisville's Institutional Repository. This title appears here courtesy of the author, who has retained all other copyrights. For more information, please contact thinkir@louisville.edu. 
INFLUENCES OF PORPHYROMONAS GINGIVALIS ON THE VIABILITY OF

ESOPHAGEAL CANCER CELLS

By

Mohammed Muddasir

\begin{abstract}
A Thesis
Submitted to the Faculty of the

School of Dentistry of the University of Louisville

In Partial Fulfillment of the Requirement for the Degree of

Master of Science in Oral Biology

Department of Oral Immunology and Infectious Diseases

University of Louisville School of Dentistry

Louisville, KY
\end{abstract}

December 2018 
Copyright 2018 by Mohammed Muddasir

All Rights Reserved 

INFLUENCES OF PORPHYROMONAS GINGIVALIS ON THE VIABILITY OF

ESOPHAGEAL CANCER CELLS

By

Mohammed Muddasir

A Thesis approved on November円uप2018

By the following Thesis Committee:

Dr. Huizhi Wang (Mentor)

Dr. David A Scott (Committee member)

Dr. Shuang Liang (Committee member) 


\section{DEDICATION}

\section{This thesis is dedicated to Almighty Allah}

Exalted is He; we have no knowledge except what He have taught us. Indeed, it is He who is the Knowing, the Wise 


\section{ACKNOWLEDGEMENTS}

First and foremost, I would like to thank Allah, Subbhana wa Tala, for his for making this beautiful journey possible.

I offer my sincerest gratitude to my mentor Dr. Huizhi Wang for his unwavering support, guidance, and patience. I cannot thank him enough for his valuable insight and expertise, which has helped me in shaping my career. It was an honor to work under him.

I would like to thank my committee members, Dr. David A. Scott and Dr. Shuang Liang for their valuable input and suggestions throughout my master's degree. Their collective knowledge and guidance helped me to finish my research project successfully. Thank you for your time and patience.

I would like to thank Dr. Zhen Gu and Dr. Xiaoxuan Duan for their valuable guidance, and technical expertise. The credit for my growth as a researcher goes to them. I thank them with my whole heart. This journey would not have been possible without them.

I would like to thank my lab members, Dr. Lanhai Lv, Dr. Yu Li, Dr. Lan Yakoumatos, Dr. Junling Ren, and Dr. Bianli Gu for their help and support during difficult times. My sincere thanks go to Mr. Edward Thompson and Mr. Gerard Buono for being part of my journey and providing administrative support and helping me with summer research. 
My gratitude goes to my parents, Mohammed Ansari and Rehana Ansari, for their endless encouragement and love throughout my life. I thank my sisters, Fareena and Ruma, for their unconditional love and support. I thank my wife Sarah Hussain for her care and affection, all through my pursuit of academic advancement. I thank my in-laws for their prayers and best wishes.

Special thanks to my friends Priyashilpa, Manoj, Sandeep, Karthik, Eren, Vivek, Anoop, Kelly, Atul, Bhushan, Sonali, Shilpa, Satya, Juili, Lahari, Himabindu, Chaitanya, Alay, Anagh, Param and Vamsi Krishna 


\begin{abstract}
एس山l1 ) / 8 ( $1 \&$ \&( 62 ) P2 $53+<52021 \$ 6 *, 1 *, 9 \$ /, 6 \square 217+(9, \$ \% /, 7<$

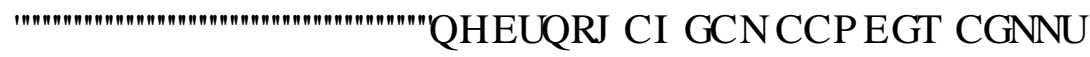

\title{
Mohammed Muddasir
}

21 November 2018

A recent study demonstrated an association between the Porphyromonas gingivalis ( $\mathrm{Pg})$ infection and the progression of ESCC (Gao et al., 2016). However, how Pg infection affects the nature of ESCC remains unknown. We examined the effects of $P g$ on the proliferation and chemotherapy drug-induced apoptosis of ESCC cells and elucidated the signaling molecules involved in these processes.

Method: Apoptosis and cell proliferation were tested using Flow cytometry and Tetrazolium salt based proliferation assays respectively. Western Blot was utilized to detect the protein expression. CDK2 and Cyclin E were knocked down in the ESCC cells through transfection. Unpaired T-test and ANOVA with post hoc Tuckey test was used to analyze relevant data $(\mathrm{p}<0.05)$.

Results: $P g$ enhanced the proliferation and reduced the chemotherapy drug-mediated apoptosis of ESCC cells possibly through Cyclin E-CDK2 pathway and Caspase-3 mediated signaling pathway, respectively. 
Conclusion: $P g$ worsens ESCC probably by promoting tumor growth and resisting chemotherapeutic drug-mediated apoptosis. 


\section{TABLE OF CONTENTS}

ACKNOWLEDGEMENTS .....................................................

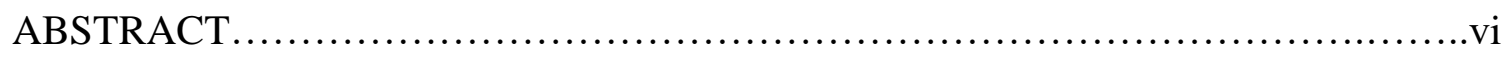

LIST OF FIGURES ......................................................

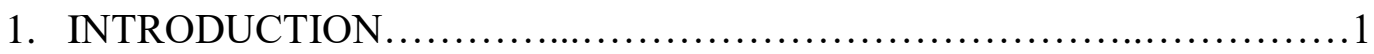

1.1 Esophagus Squamous Cell Carcinoma............................1

1.1.1 Esophagus - Basic Anatomy and Histology..............1

1.1.2 Epidemiology..................................2

1.1.3 Types of Esophageal Cancers........................3

1.1.3.1 Esophageal Squamous Cell Carcinoma..4

1.1.3.2 Histopathology of ESCC.............4

1.1.3.3 Esophageal Adenocarcinoma............4

1.1.3.4 Histopathology of EAC................5

1.1.4 Risk Factors for ESCC ............................5

1.1.5 Bacteria and Esophagus..........................6

1.1.6 Routes of Esophageal Cancer Spread..................8

1.1.7 Treatment Modalities................................8

1.2 Periodontitis..................................................... 10

1.2.1 A Brief Introduction to Periodontitis...................10

1.2.2 Overview of the Epidemiology of Periodontitis..........12 
1.2.3 Classification of Periodontal Diseases...................12

1.2.4 Classification of Periodontitis.........................14

1.2.4.1 Stages of Periodontitis..................16

1.2.4.2 Grades of Periodontitis................17

1.2.5 Theories of Periodontitis and the Emerging Role of

Porphyromonas gingivalis............................18

1.2.5.1 Non-Specific Plaque Theory...........20

1.2.5.2 Specific Plaque Theory................21

1.2.5.3 Ecological Plaque Hypothesis............21

1.2.5.4 The Polymicrobial Synergy and Dysbiosis Model of Periodontal Disease

Etiology $\ldots \ldots \ldots \ldots \ldots \ldots \ldots \ldots \ldots \ldots . . .22$

1.3 Porphyromonas gingivalis........................................24

1.3.1 Introduction to Oral Microbiota Scene..................24

1.3.2 Porphyromonas gingivalis.............................24

1.3.3 Virulence Factor of Porphyromonas gingivalis.........26

1.3.3.1 Capsule.................................26

1.3.3.2 Fimbriae.............................27

1.3.3.3 Lipopolysaccharides (LPS) .............28

1.3.3.4 Proteases..............................29

1.3.3.5 Outer Membrane Protein..................30

1.3.4 Porphyromonas gingivalis Beyond Periodontitis..........31

1.3.5 Porphyromonas gingivalis and Cancer...................31 
1.4 Cyclins and CDKs.................................................

1.4.1 Introduction to Cell Cycle...............................34

1.4.1.1 Interphase..............................35

1.4.1.2 M-phase..............................36

1.4.2 Cyclin E and CDK2 ................................. 36

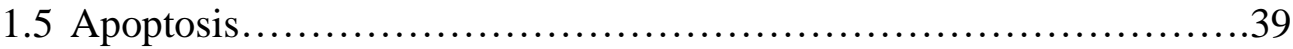

1.5.1 A Brief Introduction to Apoptosis.........................39

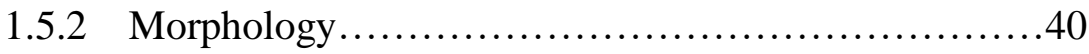

1.5.3 Morphological Changes During Necrosis................40

1.5.4 Apoptosis Versus Necrosis..............................41

1.5.5 Mechanism of Apoptosis..............................41

1.5.5.1 Intrinsic Pathway........................41

1.5.5.2 Extrinsic Mechanism.................42

1.5.5.3 A Gist of Caspase Activity..............43

1.6 Hypothesis....................................................44

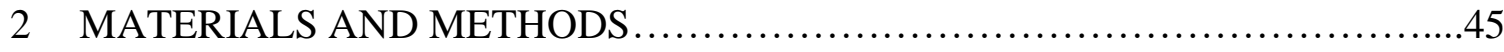

2.1 Bacteria.......................................................... 45

2.2 Cells............................................................... 45

2.3 Chemotherapeutic Drugs.........................................46

2.4 Bacterial Invasion Assay ..........................................47

2.5 MTT Proliferation Assay ..........................................48

2.6 CCK-8 Proliferation Assay ........................................48

2.7 EdU Cell Cycle Imaging Assay ....................................49 
2.8 Western Blot

2.9 Transfection .......................................................

Statistical Analysis.......................................50

2.11 Human Subjects.............................................50

3 RESULTS............................................................. 52

$3.1 P$. gingivalis Can Invade EC-9706 Cells............................52

3.2 P. gingivalis Promotes Proliferation in ESCC Cells......................55

3.3 P. gingivalis Cannot Convert Tetrazolium Salts into Formazan Except at High Concentrations............................................56

3.4 P. gingivalis Promotes Passage of ESCC Cells to S-

Phases...........................................................57

3.5 Infection of $P$. gingivalis Differentially Alters the Activity of ESCC

Cells...........................................................59

3.6 Proliferative Effect of $P$. gingivalis was Nullified When $C D K 2$ Gene was Knocked Down.................................................60

3.7 Proliferative Effect of $P$. gingivalis was Nullified When $C y c l i n E$ gene was Knocked Down................................................61

3.8 Infection of $P$. gingivalis Induces Apoptosis Resistance in EC-9706 Upon Treatment with Different Chemotherapy drugs.................63

3.9 Infection of $P$. gingivalis Induces Apoptosis Resistance in Different Esophageal Squamous Carcinoma Cells Upon Treatment of Paclitaxel. 
3.10 Infection of $P$. gingivalis Decreased Caspase 3 Activity in EC9706 cells............................................................66

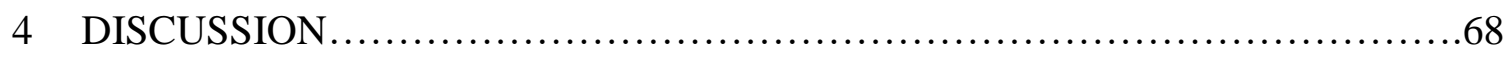

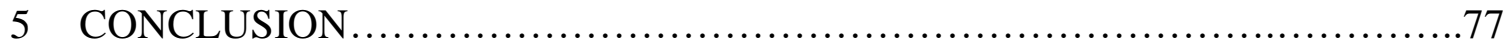

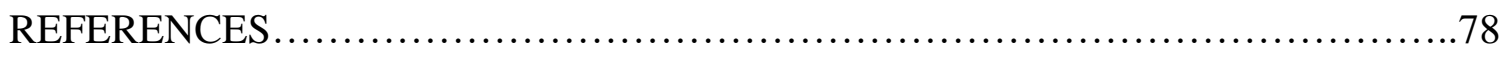

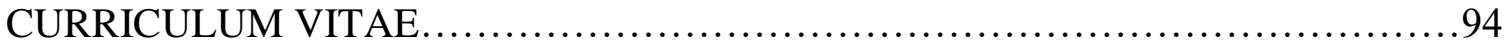




\section{LIST OF FIGURES}

$\begin{array}{ll}\text { FIGURE } & \text { PAGE }\end{array}$

1. Image of Gram-negative Porphyromonas gingivalis under 40X magnification........25

2. Confocal Image showing $P$. gingivalis invasion in (A) uninfected EC-9706 cells (control) and (B) EC-9706 infected with Porphyromonas gingivalis at two different time

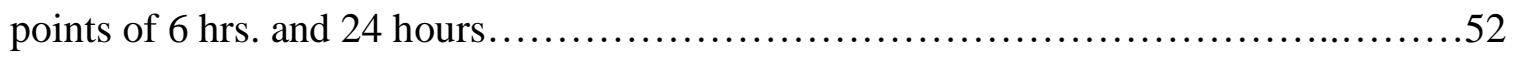

3. 3D Restructuring of the Confocal Image showing $P$. gingivalis invasion in (A)

uninfected EC-9706 cells and (B) EC-9706 infected with $P$. gingivalis..................53

4. Graph showing the ratio of Alexa Fluor 594 positive bacteria (red) containing live cell to the total live cell present in uninfected/unstimulated EC-9706 cells and in EC-9706

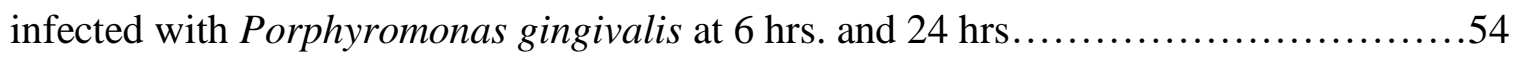

5. Graph showing the percentile of cell proliferation in $P$. gingivalis infected group when compared to uninfected group measured through MTT proliferation assay in NE3, KYSE

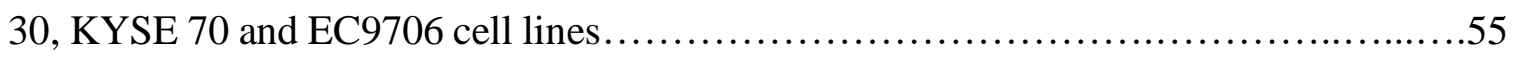

6. Graph showing the results for CCK8 proliferation assay at $450 \mathrm{~nm}$ for various

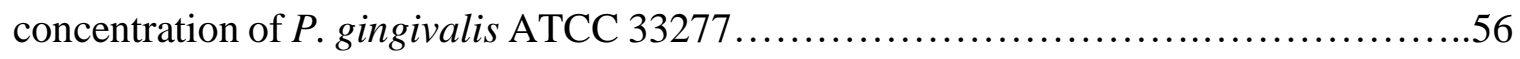

7. Confocal image showing S-phase in (A) Uninfected/unstimulated EC-9706 cells (control) and (B) EC-9706 infected with Porphyromonas gingivalis..................57

8. The percentile of Edu positive stained cells(A) Uninfected/ unstimulated EC-9706 cells (control) vs (B) EC-9706 infected with Porphyromonas gingivalis ATCC 33277..........58 
9. (A)Western blot showing Cyclins and CDK2 levels in P. gingivalis ATCC 33277 treated EC-9706 at time points 30mins, 2hrs., and 4hrs (B) A graph showing Cyclins and CDK levels in P. gingivalis ATCC 33277 treated EC-9706 at time points 30mins, 2hrs. and 4hrs. .59

10. Graph showing reduced limited proliferation in $P$. gingivalis treated CDK2 knocked down EC9706 cells. .60

11. Graph showing the result of CCK8 proliferation assay for P. gingivalis ATCC 33277 treated, CDK2 knocked down EC9706 cells. 61 12. Graph showing the result of CCK8 proliferation assay for $P$. gingivalis ATCC 33277 treated, Cyclin E knocked down EC9706 cells....

13. Image showing the results of flow cytometry in EC9706 on treatment with neoadjuvant drugs in $P$. gingivalis ATCC 33277 infected samples....

14. Graph showing the apoptosis resistance in NE3, KYSE-30, and KYSE-70 on treatment with Paclitaxel in $P$. gingivalis ATCC 33277 infected samples .66

15. Western blot showing the Caspase 3 activity in P. gingivalis ATCC 33277 infected EC9706 cells (106 cells/well) at time points $12 \mathrm{hrs}$. and $24 \mathrm{hrs}$ 67 


\section{INTRODUCTION}

\subsection{Esophagus Squamous Cell Carcinoma}

\subsubsection{Esophagus - Basic Anatomy and Histology}

Esophagus, also commonly referred to as food-pipe, is a tube-like organ that connects the pharynx and stomach. In adults, it is about $18-26 \mathrm{~cm}$ long. It starts at the pharyngoesophageal junction at the C5-C6 level and descends passing through the diaphragmatic hiatus at T-10 to end at the cardia of the stomach at T11 level. Both entry and the exit is "guarded by" upper and lower esophageal sphincters respectively.

The wall of the esophagus is divided into- the mucosa, which lines the lumen; submucosa, muscularis propria, and the outermost adventitia. Unlike other gastrointestinal tract organs, the esophagus lacks an outer serous layer. This allows an easy spread of a tumor and makes it surgically harder to treat. A non-keratinized stratified squamous epithelium line the mucosa of the esophagus underneath which, there is a thin layer of connective tissuelamina propria and a muscularis mucosae. Muscularis mucosae have irregularly arranged smooth muscle fibers. It grows in thickness distally. The submucosa layer contains glands as well as immune cells, vascular network (Heller's plexus), nerve cells (Meissner's 
Plexus), etc. Muscularis propria is majorly composed of muscles. While the proximal half is richer in skeletal muscle fiber, distally it is composed primarily of smooth muscle. In between, where a mixture of both is seen, is called the transition zone (Kuo \& Urma, 2006) (Yazaki \& Sifrim, 2012).

\subsubsection{Epidemiology}

Esophageal carcinoma is lethal. Esophageal cancer was the eighth most common cancer worldwide, comprising $3.2 \%$ (456,000 cases) of the new cancer burden, and ranked sixth in mortality with an estimated 4.9\% (400,000 deaths) of cancer deaths. Esophageal cancer is estimated to be the eleventh leading cause of cancer death in the United States between 2009-13. Esophageal patients are estimated to have poor survival with an overall ratio of mortality to the incidence of 0.88 . An estimated $80 \%$ of the primary esophageal neoplasms are malignant (Pickens \& Orringer, 2003). Of the estimated 456,000 cases, an estimated $398,000(87.28 \%)$ were squamous cell carcinoma while remaining were adenocarcinoma and other cancers. (Arnold, Soerjomataram, Ferlay, \& Forman, 2015). The global incidence of esophageal squamous cell carcinoma was 5.2 per 100,000 with a global, male to female ratio at 2.7 (Bray, Ren, Masuyer, \& Ferlay, 2012.) (Ferlay et al., 2013).

It exhibits a marked geographic variation in incidence. Areas with notably higher incidence include China, South America, western Europe, southern Africa, Japan and regions of former USSR. Within these regions, there are pockets where incidence can be 10 to 50 times higher. Such areas include northern and central China, southern Thailand, northern 
Italy, mountainous regions of Japan, coastal parts of Iran and certain French provinces. In the United States, the District of Columbia and the coastal regions of the southern states reported the highest incidence. ESCC has a higher incidence in the urban areas of the United States and is particularly common in African-American men, with an overall incidence of approximately 3 to 4 per 100,000 people (Cook, 2011). The incidence of ESCC increases with age and peaks in the seventh decade of life. Around $30 \%$ of the patients exhibit metastasis at the time of presentation, and 30 percent have regional cancer at the time of undergoing primary surgery (Y. Zhang, 2013)

The incidence of esophageal adenocarcinoma is on the rise in Europe. In North America, the United States and Canada have the highest incidence rates. Its rate of incidence is highest when compared to any other type of cancer (Pickens \& Orringer, 2003). In 1975, esophageal adenocarcinoma affected four people per million, in 2001 this equation changed to 23 people per million making it the fastest growing variant of cancer in the United States. In the 70s, esophageal squamous cell carcinoma (ESCC) was responsible for more than $90 \%$ of the esophageal carcinoma cases in the United States. However, for some unknown reasons, Adenocarcinoma has overtaken it, representing about $80 \%$ of the reported cases (Napier, Scheerer, \& Misra, 2014).

\subsubsection{Types of Esophageal Cancers}

The two most common types of esophageal carcinoma are esophageal squamous cell carcinoma and esophageal adenocarcinoma. There are other types of esophageal cancer too 
including lymphomas, rhabdomyosarcoma, melanoma, etc. However, they form a tiny percentage of the overall reported cases.

\subsubsection{Esophageal Squamous Cell Carcinoma.}

ESCC is associated with the esophageal middle third. It produces symptoms like difficulty in swallowing and loss of hunger that leads to weight loss. It arises from the squamous lining of the esophagus. In most cases, the patients suffered from chronic esophagitis.

\subsection{Histopathology of ESCC}

ESCC can show variable differentiation. A well-differentiated ESCC show keratin pearls, cell keratinization, intracellular bridges, etc. Poorly-differentiated ESCC lack these features and is determined to be of epithelial in origin by its location in situ, the presence of IEN (Intraepithelial dysplasia), the pattern of infiltration, using immunohistochemical markers like CK5/6 or p63, etc. Moderately-differentiated ESCC show intermediate features (Shilpa Jain \& Dhingra, 2017).

\subsubsection{Esophageal Adenocarcinoma}

Esophageal adenocarcinoma is most often related to obesity, GERD, Barrett's esophagus etc. It arises from the glandular portion of the esophageal lining. It is believed thatthe gastrict contents irritate the mucosal lining leading to the disease. Often a carcinoma in the 
lower third of the esophagus most likely is an esophageal adenocarcinoma. In some cases, they might occur next to ESCC giving rise to something called a Collision tumor (Maleki, Shekarriz, Nosrati, \& Orang, 2015).

\subsection{Histopathology of EAC}

EAC can present as an ulcerative or exophytic mass. They are gland forming tumors with tubular, tubulopapillary or papillary growth patterns. A well-differentiated tumor shows more than $95 \%$ gland formation, moderately-differentiated shows anywhere between $50 \%$ to $95 \%$ gland formation. Poorly-differentiated tumor has less than $50 \%$ of glandular formation (Shilpa Jain \& Dhingra, 2017).

\subsubsection{Risk Factors for ESCC}

Cigarettes, obesity, red meat, alcohol, tobacco-smoking, opium consumption, drinking hot beverages, poor oral health, low intake of fresh fruit and vegetable and low socioeconomic status is associated with a higher risk of esophageal squamous cell carcinoma (Y. Zhang, 2013). ESCC risk increased with consumption of alcohol, with higher consumption corresponding to the higher risk of the disease. The incidence of ESCC dramatically increases in the presence of any factor that causes chronic irritation and inflammation. Consumption of alcohol and smoking promotes inflammation of the esophagus, but when done together they have a synergistic effect. The effect supposedly doubles than their sum individually. The relative risk of men who used both heavy tobacco and alcohol was 35.4 
in white males and 149.2 in black males (Brown et al., 1994). Though studies are underway to understand the possible mechanism behind the process it is believed that the alcohol acts as a solvent for the carcinogens present in the tobacco smoke, and allow them easy access inside the esophageal epithelium (Napier et al., 2014). Consumption of hot beverages and pickles have been implicated as a possible risk factor too, but the evidence in this regard is limited.

Lack of fresh fruit and vegetables and micronutrient deficiency is a risk factor for the disease (Y. Zhang, 2013). Plasma riboflavin levels have been correlated with prognosis as well as risk. Other micronutrients like $\beta$-carotene, vitamin-E, and selenium said to have reduced mortality. Exposure to chemicals (polycyclic aromatic hydrocarbons and nitrosamine) is seen as a cause of ESCC (Napier et al., 2014). Studies in northern Iranian population linked increased urinary levels of PAH metabolites with increased risk. Similar studies in China and Brazil yielded similar results (Liang, Fan, \& Qiao, 2017). Carcinogens, and a potential causative agent of ESCC, nitrosamines, have been found in some salted vegetables and certain preserved fish varieties (Napier et al., 2014).

\subsubsection{Bacteria and Esophagus}

It was Yang et al. who first distinguished between the microbiota of a healthy and a diseased esophagus. They noticed a shift from Gram-positive rich microbiota dominated by Firmicutes in healthy esophageal epithelium to a more Gram-negative rich microbiota 
(Veillonella, Prevotella, Bacteroidetes, Haemophilus, Neisseria, Campylobacter, Fusobacteria, etc.) in mucosa associated with GERD related esophagitis and BE.

Works to look into the microbiota associated with esophageal cancer has been there for three decades. The earlier studies suffered from a severe limitation of culture-dependent approach, the absence of control groups and due to the lack of histological differentiation between EAC and ESCC. Narikiyo et al. were among the first to characterizes the microbiota of esophageal cancer patients. However, it is unclear if the patients were suffering from ESCC or EAC or both. Their study demonstrated unusual domination by Treponema denticola, S. mitis, and S. anginosus in esophageal cancer tissue.

The presence of Campylobacter concisus, which is seen in high numbers in GERD and BE, play a role in EAC progression. C. concisus colonization is believed to cause inflammatory dysbiosis which drives EAC. However, their lower prevalence from actual EAC lesion raises questions. Some authors have tried to explain this phenomenon using driver pathogen model.

Further, recent studies have suggested that poor microbial diversity promotes esophageal squamous dysplasia. A decrease in abundance of Lautropia, Bulleidia, Catonella, Corynebacterium, Moryella, Peptococcus and Cardiobacterium was noted. Chen et al. reported a relative abundance of Prevotella, Streptococcus, and Porphyromonas in ESCC cases (Di Pilato et al., 2016; Peters et al., 2017; Chen et al., 2015). A recent epidemiological 
study has shown the Porphyromonas gingivalis, a gum bacterium to be associated with ESCC.

\subsubsection{Routes of Esophageal Cancer Spread}

Esophageal cancer is notoriously aggressive. It can spread through direct invasion, lymphatic spread, and hematogenous metastasis. The esophagus is lacks a serous layer like other GI tract organs that contributes to local extension of esophageal cancer. In the absence of an anatomical barrier, cancer quickly spread into nearby structures of neck and thorax (Kuo \& Urma, 2006) (Yazaki \& Sifrim, 2012).

The esophagus has a rich lymphatic supply. The lymphatics in the upper half of the esophagus carry the lymph upwards while the lower half carry it downwards. All the lymphatics of the organ are well connected. It results in the spread of the secondary tumor in any direction (Napier et al., 2014)

\subsubsection{Treatment Modalities}

There are three primary treatment modalities for treating ESCC. These are- surgical approach, chemotherapy, and radiological treatment. The stage of cancer determines the treatment modality or the combination of the treatment modalities to be employed. 
Surgical approach involves esophagectomy. Different approaches are prescribed depending on the extent, the location of the tumor, etc. Chemotherapy and radiotherapy are other critical modalities of treatment. According to the National Comprehensive Cancer Network 2013 guidelines a triple therapy drug regimen that includes paclitaxel/carboplatin, cisplatin/fluoropyrimidine, and oxaliplatin/fluorouracil. The recommended radiation dose is 41.4-50.4 Gy (Napier et al., 2014). 


\subsection{PERIODONTITIS}

\subsubsection{A Brief Introduction to Periodontitis}

American Association of Periodontology defines Periodontium as 'the tissues that invest and support the teeth including the gingiva, alveolar mucosa, cementum, periodontal ligament, and alveolar supporting bone' ("PERIODONTIUM - AAP Connect," n.d.). The disease that inflicts these structures are Periodontal Diseases, of which gingivitis and periodontitis are the most common. Gingivitis is limited to the gums, while periodontitis is more extensive, and involves underlying bone and other structures of the periodontium. Gingivitis is seen during the initial phases as the inflammation of the gingival tissue. Since it involves soft tissue structures and is seen during early phases of the Periodontal disease, it is reversible in most of the cases.

'Periodontitis is characterized by microbially- associated, host-mediated inflammation that results in the loss of periodontal attachment'. Periodontitis destroys tooth-supporting structures that lead to gingival recession, periodontal pocket formation and the loss of the surrounding alveolar bone. As a result, the tooth becames mobile and left untreated will lead to exfoliation. The disease process involves activation of the molecular pathway that leads to activation of host mediators that ultimately causes loss of periodontal ligament fibers, apical migration of junctional epithelium and apical spread of bacterial biofilm (Tonetti, Greenwell, \& Kornman, 2018). 
However, this definition of periodontitis came under severe criticism in 2017 because of limitations in its applicability. Traditionally, attachment loss is determined by circumferential assessment of the erupted dentition using a standardized periodontal probe in conjunction with radiographical evidence of marginal bone loss. It is to be noted that some diseases other than periodontitis can cause loss of attachment and radiographical evidence have limited application. Limitation of radiographs is due to the fact they are not specific and may not register bone loss due to mild to moderate periodontitis.

It created a need for a more patient-based definition of periodontitis. It defines a periodontal case as Interdental Clinical loss of Attachment (CAL) is detectable at $\geq 2$ non-adjacent teeth, or buccal or oral $\mathrm{CAL} \geq 3 \mathrm{~mm}$ with pocketing $>3 \mathrm{~mm}$ is detectable at $\geq 2$ teeth, and the observed CAL cannot be a byproduct of non-periodontal causes such as 1) gingival recession of traumatic origin; 2) dental caries extending in the cervical area of the tooth; 3) the presence of CAL on the distal aspect of a second molar and associated with malposition or extraction of a third molar, 4) an endodontic lesion draining through the marginal periodontium; and 5) the occurrence of a vertical root fracture.

The new classification is aimed at 1) Identification of a patient as a periodontitis case, 2) Identification of the specific form of periodontitis, and 3) Description of the clinical presentation and other elements that affect clinical management, prognosis, and potentially broader influences on both oral and systemic health (Tonetti et al., 2018). 


\subsubsection{Overview of the Epidemiology of Periodontitis}

Severe periodontitis is ranked at six most prevalent condition affecting $11 \%$ of the global population (Marcenes et al., 2013). It affected 573 million people worldwide leading to 276 million patients to lose their teeth (Kassebaum et al., 2017). According to estimates, over $47 \%$ of adult US population (30 years and older) suffers from periodontitis. Around $30 \%$ of this population suffers from moderate periodontitis while about $8.5 \%$ suffers from severe periodontitis. For adults over 64 years of age, $64 \%$ of them suffers from moderate to severe periodontitis. Epidemiological studies show that periodontitis has a predilection towards older individuals; males; Mexican Americans; individuals with poor economic status and smokers. (Eke, Dye, Wei, Thornton-Evans, \& Genco, 2012).

\subsubsection{Classification of Periodontal Diseases}

In the 1989 Periodontitis was classified based on the age of onset and rate of progression as Prepubertal, Juvenile, Adult and Rapid-Onset. In 1993, this classification was simplified as Adult and Early-onset periodontitis. However, in the absence of evidence, this classification was abandoned in 1999. The 1999 Classification system of Periodontal and Peri-implant diseases classify periodontal diseases based on the unique feature of different phenotypes into four different forms as

- Necrotizing periodontitis

- Aggressive Periodontitis

- Chronic Periodontitis 
- Periodontitis as a manifestation of systemic diseases

The primary objective of this classification was to differentiate the more common forms of periodontitis, chronic and aggressive periodontitis, from other rarer conditions like the necrotizing form and rare genetic disorders. This classification devised major and minor criteria and by default if the case of periodontitis did not satisfy the criteria for the aggressive form it was considered to be the chronic variant. However, in practice clinicians faced significant challenges as many of these criteria overlapped Furthermore, aggressive and chronic periodontitis have similar pathophysiology with little evidence that both are distinct disease and not variants of the same disease. (Tonetti et al., 2018).

The 2017 World Workshop on the Classification of Periodontal and Peri-implant Disease and Conditions proposed a new classification system based on pathophysiology. According to the new classification, periodontal diseases are classified on the basis of pathophysiology as Necrotizing Periodontal diseases, Periodontitis and Periodontitis as a manifestation of systemic diseases. For Periodontitis that arose a direct manifestation of systemic diseases, it follows the classification of the primary disease as laid down by the international statistical classification of disease and related health problem codes (Tonetti et al., 2018).

Necrotizing ulcerative periodontal diseases is a group of disorders with similar etiologies comprising of necrotizing ulcerative gingivitis, ulcerative periodontitis, and necrotizing stomatitis. These different diseases are different stages of the same disease with various extent of destruction. Necrotizing ulcerative gingivitis (NUG) is limited to the gingival tissue. It is often referred to as trench mouth disease, as it was very prominent among the 
soldiers fighting the World War II trenches. In cases where the NUG extends into the underlying periodontal apparatus resulting in the loss of bone and CAL, it is classified as Necrotizing ulcerative periodontitis (NUP). If left untreated it may continue to involve deeper tissues beyond the mucogingival line to include lip, cheek or tongue and is referred to as Necrotizing stomatitis (Hu, Kent, Lennon, \& Logan, 2015; Miranda-Rius, BrunetLlobet, \& Lahor-Soler, 2018).

At the beginning of the $20^{\text {th }}$ century due to lack of evidence against any specific bacteria, it was not considered as a specific infection but as an opportunistic one that is caused by indigenous oral microflora. Around the same time, other theories like, vitamin-deficiency theory and debilitating theory, were put forth. Recent studies have shown that in these cases, there is an imbalance in the normal oral flora with reduced diversity. There was an increase in Provetella genus with loss of Capnocytophaga and Fusobacteria genera. However, increase Provetella is often associated with other pathogens and has never been reported as a primary causative agent. It is likely that Provetella flourishes in the disease condition and may not be the actual cause of the disease (Srour, Marck, \& Baratti-Mayer, 2017).

\subsubsection{Classification of Periodontitis}

Older classification systems did not address the past impact of the disease on the patients, treatment approach, and management, or the progression of the disease. The new classification classifies the Periodontitis into Stages and Grades, like TNM staging in 
Cancer. The stages of the disease record the severity, treatment complexity and the extent and distribution, whereas the grading looks at the progression of the disease, associated risk factors, systemic impact of periodontitis and biomarkers. Though attempts were made by the earlier systems to record the severity of the disease, there were limitations. With improved techniques clinicians are able better manage certain conditions which affect its severity. Another limitation was, with the loss of the most diseased tooth led to an apparent decrease in the severity of the disease. There was a need to address the complexity of management of a case. The inclusion would help the clinicians to decide on the competence and experience level required to manage the case. It is especially helpful in the case of general dentists as it makes it easier for them to decide when to refer the patient.

The staging of the disease envisages helping identify the severity and extent of the disease based on currently measurable extent of destruction of the tissue that is attributable to periodontitis and to assess the complexity of different factors that may determine the complexity of future treatment plan. The grading mechanism aims at estimating future risk of periodontitis progression and responsiveness to standard therapeutic principles, to guide the intensity of therapy and monitoring. 


\subsection{Stages of Periodontitis}

\section{Stage I}

It represents the initial stages of the disease and the early stages of attachment loss with a maximum interdental CAL of 1 to $2 \mathrm{~mm}$ and/or a maximum probing depth equal to or less than $4 \mathrm{~mm}$. The bone loss is limited to the coronal half of the coronal third, and much of it is horizontal.

\section{Stage II}

It represents established periodontal case. The clinical management of the case remains relatively simple. An interdental CAL of 3 to $4 \mathrm{~mm}$ is seen and/or a maximum probing depth of equal to or more than $5 \mathrm{~mm}$. The bone loss is limited to coronal third being mostly horizontal $(15 \%-33 \%)$.

\section{Stage III}

It represents severe periodontitis which has produced significant damage to the periodontal apparatus and had the potential for tooth loss. An interdental CAL of equal to or more than $5 \mathrm{~mm}$ and/or a probing depth equal to more than $6 \mathrm{~mm}$ is seen. The bone loss extends to or beyond root mid-third and/or a vertical bone loss of $3 \mathrm{~mm}$ or more. There can also be 
furcation involvement of class II or III or moderate ridge defect. Stage III cases have a history of tooth loss due to periodontitis involving four teeth or less.

\section{Stage IV}

It represents an advanced periodontitis case with extensive tooth loss. Patients have lost 5 or more teeth due to periodontitis. It has all the characteristics of a Stage III periodontitis but has an added complexity due to the need for complete rehabilitation.

The extent (localized or generalized) and the distribution(molar/incisor) cut across all the four stages of periodontitis

\subsection{Grade of Periodontitis}

It is to be noted that irrespective of the stage of the periodontitis it may progress at different rates. Hence, the treatment outcome might differ from individual to individual

\section{Grade A}

It represents a slow rate of progression. In spite of the presence of heavy biofilm deposits, the progression of the disease is relatively slow. There is no bone loss over a period of 5 years. The patient is a non-smoker and a non-diabetic and has a high sensitivity $\mathrm{C}$ reactive protein (hsCRP) less than $1 \mathrm{mg} / \mathrm{L}$ 


\section{Grade B}

It represents a moderate of progression. The progression of the disease matches the amount of biofilm. There is a less than $2 \mathrm{~mm}$ of bone loss over a period of 5 years. Patients smoke less than 10 cigarettes per day and/or HbA1c less than 7\%. The hsCRP is $1-3 \mathrm{mg} / \mathrm{L}$.

\section{Grade C}

It represents a rapid rate of progression. The amount of destruction far exceeds the amount of biofilm deposit. There is a bone loss of $2 \mathrm{~mm}$ or more over 5 years. The patient can be a smoker with consumption of above 10 cigarettes per day. The patient can be diabetic with HbA1c equal to more than $7 \%$ in patients. The hsCRP level exceeds $3 \mathrm{mg} / \mathrm{L}$.

In case there is a conflict between the criteria always a higher stage or grade defines the case (Tonetti et al., 2018).

\subsubsection{Theories of Periodontitis and the Emerging Role of Porphyromonas gingivalis}

Periodontitis is known to afflict humankind since the dawn of the civilization. Ancient records and paleopathological studies have shown gum diseases, and loosening of teeth are as old as humanity. The ancient Egyptians and Chinese describe periodontal diseases as an inflammatory condition. Hippocrates (460-335 B.C.) is seen describing this affliction in 
his works. In later years, Hebrews, Romans, and Arabs all have tried to describe the disease and tried to provide the treatment for the same.

Pierre Fauchard is credited with a modern description of the disease in his treatise Le chirurgien dentist. Fauchard identified calculus build-up as the cause of the disease and advised its removal using special instruments. He prescribed the use of dentifrices and mouthwashes to prevent the buildup calculus and advised splinting the loose tooth. An Englishman, John Hunter, proposed that the inflammation process in the gingiva as an important factor that causes the dissolution of the surrounding alveolar bone. Later on, Riggs in his article Pyorrhea Alveolaris placed the responsibility of the disease on calculus and other foreign bodies that made the tooth structure rough. Riggs was convinced that the disease was the byproduct of local factors(Löe, 1993).

While the Localists like Riggs dominated the United States scene; Europeans increasing believed that nutritional deficiencies and imbalances, and other systemic conditions is caused by the periodontitis. This led to a localist versus generalist debate (Hujoel, Zina, Cunha-Cruz, \& Lopez, 2012).

W.D. Miller in 1886 was the first to relate the oral diseases to germ theory. According to him, pyorrhea alveolaris was caused by various bacteria working together but none in particular. Hence, in essence, what Miller proposed over a 100 years ago can be interpreted as a multifactorial disease resulting from a nonspecific infection and disturbance of normal 
host-microbe relationship. However, he did not put forth any substantial evidence supporting his case (Löe, 1993).

In 1911, W. Hunter proposed focal infections theory which hypothesized that oral infections could act as a source of sepsis. He proposed the use of the gold crown, gold caps, gold bridges, etc. to build a "gold mausoleum to contain sepsis." It led to the practice of removing teeth for no good reason other than the notion that periodontal lesion and necrotic pulp were life-threatening time bombs (Löe, 1993).

Works of Waerhaug and others in the early 1950s re-introduced plaque into the picture. They demonstrated the importance of plaque as the etiological agent in periodontal disease and that by preventing plaque formation one can avoid periodontal disease. Epidemiolocal studies further bolstered this stand. This finding that periodontitis is an infectious disease change the treatment approach as well as led the search for the causative microorganism (Löe, 1993).

\subsubsection{Non-specific plaque theory}

It was believed that poor oral hygiene led to gingivitis which later progressed to periodontitis. It was proposed that in the absence of proper oral hygiene the gingival crevice gets colonized by complex indigenous microflora causing a non-specific inflammation of the gingiva. The sub-gingival plaque was believed to be a downgrowth of supragingival plaque. A combination of indigenous bacteria, rather than a single species, produced 
gingivitis that progressed to periodontitis (Theilade, 1986). This is referred to as Domino theory. In order to prevent periodontitis, it was essential that plaque must be controlled to prevent other two conditions from developing (Hujoel et al., 2012). However, unlike gingivitis which is closely related to bacterial colonization and level of plaque accumulation, periodontitis has more specific and complicated etiology. This theory focused on the quantity of plaque rather than its quality and thus was unable to explain periodontitis cases with minimal plaque levels.

\subsubsection{Specific Plaque theory}

Specific Plaque proposed that a specific 'complex of organisms' in responsible for periodontitis. The 'Red complex' was indicated to be a major player in periodontitis. This complex was composed of $P$. gingivalis.; T. forsythia and T. denticola (Socransky, Haffajee, Cugini, Smith, \& Kent, 1998). This hypothesis proposed a more targeted approach. It proposed the use of antimicrobials as an effective measure to counter periodontitis (Nisha, 2017).

\subsubsection{Ecological Plaque Hypothesis}

This theory proposed that, in healthy individuals, the oral bacterial population remains relatively stable. This relative stability was attributed to synergistic and antagonistic microbial interactions. However, an imbalance in this homeostasis leads to a shift in the balance of microflora, thereby predisposing sites to disease. Changes in local environment 
influence the occupant microflora population. It was proposed that disease can be treated by targeting the offending organism as well as by interfering with the process that led to the loss of homeostasis (Marsh, 1994).

\subsubsection{The Polymicrobial Synergy and Dysbiosis Model of Periodontal Disease Etiology}

The colonizing bacteria organize themselves in a physiologically compatible communicative community. The introduction of a keystone pathogen (a pathogen with a disproportionately large effect on its environment relative to its abundance) like $P$. gingivalis alters the dynamics of the community. Communication between $P$. gingivalis and other organisms which in general acts as commensals, accessory pathogen (an organism that while commensal in a particular microenvironment, nonetheless supports or enhances the virulence of another organism), etc. facilitate synergy and causes pathogenicity. This new community of organism is called as a dysbiotic community. As this dysbiotic community continues to grow, it stimulates an inflammatory response. In a susceptible host, this inflammatory response is often frustrated and misdirected which leads to excessive destruction of host tissue facilitating the flourishment of an inflammophilic community which sustains itself on the inflammation derived breakdown-nutrients. However, in later stages, the driver bacteria ( $P$. gingivalis) is out-competed by passenger bacteria (Lamont \& Hajishengallis, 2015). However, it must be kept in mind that the current model of PSD is based on a mouse model. $P$. gingivalis is not a natural inhabitant of mouse oral cavity and that at the time of writing there were no human studies to support 
the PSD model. How P. gingivalis presence leads to periodontitis remains to be fully understood, but there is no denying the fact that prefers to exist in a plaque around the teeth in the subgingival sulcus of the human oral cavity. When seen in the context of Gao et al. study it indicates that eradication of oral pathogen could potentially contribute to a reduction in the overall ESCC burden (Gao et al., 2016). 


\subsection{Porphyromonas gingivalis}

\subsubsection{Introduction to Oral Microbiota Scene}

It is estimated that the oral cavity of a healthy human adult harbors at least six billion bacteria with representation from over 700 species (Aas, Paster, Stokes, Olsen, \& Dewhirst, 2005). Apart from bacteria, the oral cavity is home to various species of fungi mycoplasma, protozoa, and viruses. However, this diverse oral microbial community is more or less stable and is referred to as climax community. However, in a diseased condition like caries or periodontal diseases, an imbalance can be seen in the oral resident microbiota favoring potentially pathogenic microorganism (How, Song, \& Chan, 2016a).

\subsubsection{Porphyromonas gingivalis}

Porphyromonas gingivalis is a non-motile, asaccharolytic, Gram-negative, rod-shaped, obligate anaerobic bacteria (Bostanci \& Belibasakis, 2012). It forms black pigmented colonies on blood agar plates. Porphyromonas gingivalis primarily occupies the subgingival sulcus in the human oral cavity with a reported frequency of $87.75 \%$ in patients with chronic periodontitis. However, different studies peg this number at different levels ranging from $40-100 \%$. Some of the studies have shown a substantial increase in $P$. gingivalis at periodontitis sites with virtually low to no detection at plaque-associated gingivitis (How, Song, \& Chan, 2016b). P. gingivalis is shown to be found in deep gingival pockets in a higher frequency than when compared to the shallow pockets. It metabolizes 
amino acids for energy when sugar levels are low. It is said to be secondary colonizer owing to its obligate anaerobic nature (Bostanci \& Belibasakis, 2012). It is often found to adhere to Streptococcus gordonii and $P$. intermedia. $P$. gingivalis is often associated with T. denticola and T. forsythia in advanced lesions. Further, in almost all the cases $P$. gingivalis antibodies were found to higher in periodontitis cases. This evidence suggests Porphyromonas gingivalis is strongly associated with periodontitis (How et al., 2016a), and has been often described as a pathobiont (Cugini, Klepac-Ceraj, Rackaityte, Riggs, \& Davey, 2013). A pathobiont is an organism which has a pathogenic potential. However, under normal circumstances lives as a symbiont. It is thought that Porphyromonas gingivalis is a natural inhabitant of the human oral cavity. However, a shift in the microbial composition is associated with its growth.

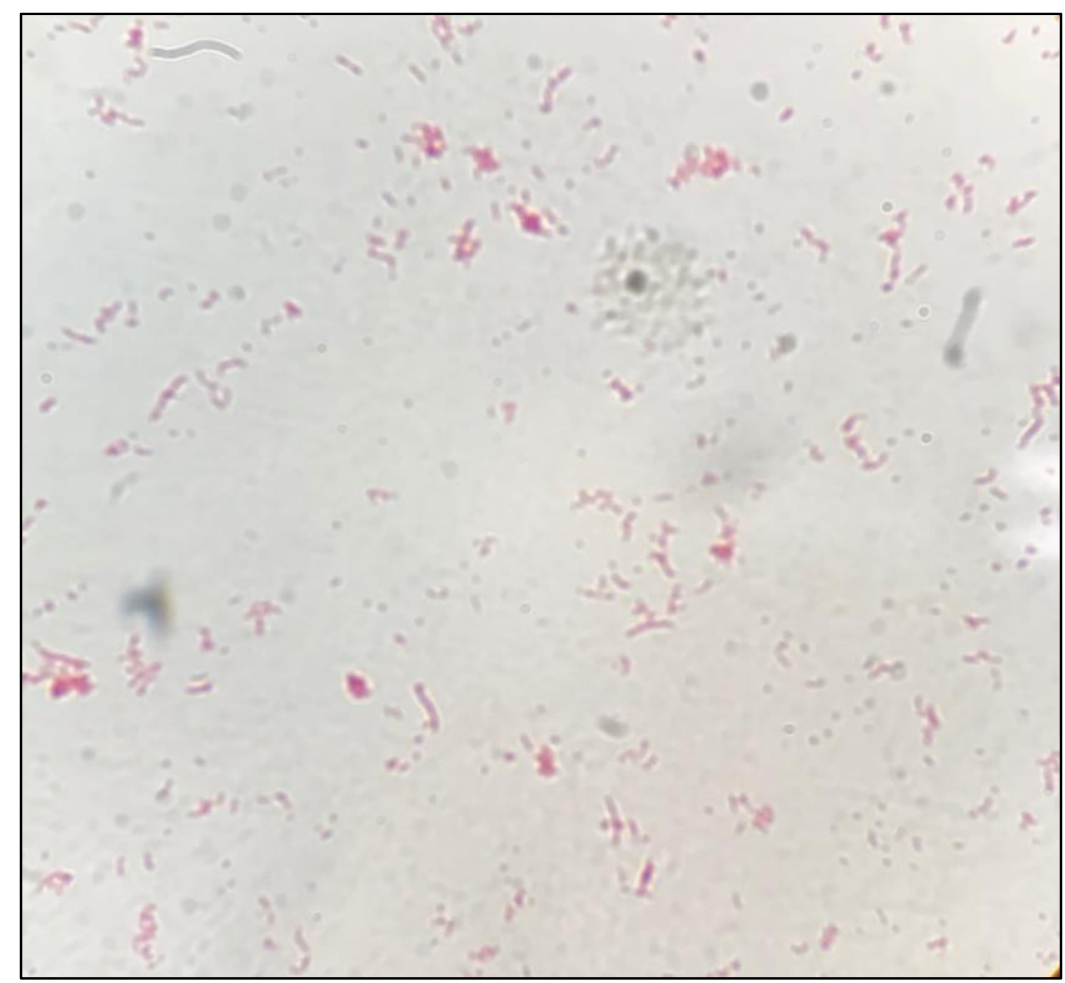

Figure 1: Image of Gram-negative Porphyromonas gingivalis under 40X magnification. 
As discussed earlier, the PSD model hypothesize that $P$. gingivalis interact with other members of the host microbiota and helps in the progression of the disease.

\subsubsection{Virulence Factor of Porphyromonas gingivalis}

Porphyromonas gingivalis contributes towards dysbiosis leading to an inflammatory onslaught. It possesses virulence factors which not only contributes towards its survival against host attack but also promote inflammation. Virulence factors may be defined as the constituents or metabolites of an organism which are essential in various stages of the life cycle and cause damage to the host. The expression of these virulence factors is found to be dependent on the character of the external environment.

\subsubsection{Capsule}

It forms the outermost layer of the organism and contributes towards its attachment to host tissues. Adherence to host tissue provides the organism a sort of environmental permanence and help it resist against the flushing action of saliva and gingival crevicular fluid (GCF). The chemical composition of the capsule is found to vary between strains of $P$. gingivalis. This difference is usually due to the composition of the sugar. $P$. gingivalis is known to display six capsular antigens (1-6) (Laine, Appelmelk, \& van Winkelhoff, 1997).

Highly capsulated strains are hydrophilic, lower in density and autoagglutination. It is thought capsule provides resistance against phagocytosis, perturbation of gingival 
epithelial cells and decreased induction of neutrophils (Singh et al., 2011) (How et al., 2016). $P$. gingivalis was able to modulate the immune response by reducing the production of interleukin-1 (IL-1), IL6 and IL-8. Capsule protects $P$. gingivalis against small antimicrobial peptides like defensins. $P$. gingivalis utilizes its capsular protein to interact with other bacteria like Fusobacterium nucleatum in its environment (Binder Gallimidi et al., 2015). Capsule prolongs the survival of $\mathrm{P}$. gingivalis and helps it escape inflammatory ultimately increasing long-term inflammatory response.

\subsubsection{Fimbriae}

$P$. gingivalis possess thin hair like proteinaceous structures which arises from the outer membrane of the bacterial cell. They vary in their length and can measure from 3-25m $\mu \mathrm{m}$. $P$. gingivalis expresses two distinct types of fimbriae on its surface- long or major fimbriae encoded by fimA gene and short or minor fimbriae encoded by $m f a l$ gene.

The FimA protein can weigh from 40.5 to $49 \mathrm{kDa}$ based upon the strain. There are six types of these fimbriae (Type I-V and Ib) based on the amino-terminal, and the DNA sequence. Type I stains like $P$. gingivalis ATCC 33277 are abundantly fimbriated, and Type IV strains are poorly fimbriated (W. Zhang, Ju, Rigney, \& Tribble, 2011).

Minor fimbriae are demonstrated to stimulate the production of IL- $1 \alpha$, IL-1 $\beta$, IL-6, and TNF- $\alpha$ by macrophages(Amano, Nakagawa, Okahashi, \& Hamada, 2004). It is hypothesized that minor fimbriae are responsible animal bone resorption in animal models. 
Fimbriae help $P$. gingivalis to bind and invade host cells such as host phagocytes, osteoclast, and epithelial cells. It also helps the bacteria to adhere to other commensal bacteria such as Streptococci gordonii, extracellular matrix proteins, and salivary proteins. Fimbriae adhere to cellular $\alpha_{5} \beta_{1}$-integrin which causes rearrangement of actin cytoskeleton resulting in the internalization of the bacteria with the help of lipid rafts, dynamin, etc. There is emerging evidence relating the fimbriae with atherosclerosis progression by reducing regulatory T cells (Tregs) (How et al., 2016).

\subsubsection{Lipopolysaccharides (LPS)}

Lipopolysaccharide is a component of the bacterial outer membrane. It is a large molecule and over $10 \mathrm{kDa}$ in size. It maintains structural integrity and controls the entry of molecules into the bacterial cell. It consists of a distal polysaccharide (O-antigen), a non-repeating core and a hydrophobic domain known as lipid A (endotoxin). Lipid-A is the innermost component and is biologically active (Sumita Jain \& Darveau, 2010)

$P$. gingivalis LPS has multiple Lipid-A moieties. The expression of Lipid-A structure can be manipulated by hemin concentration and temperature; as a result, PgLPS differs significantly under different environmental conditions. The two most predominant isoforms are a penta-acylated form (LPS 1690$)$ and tetra-acylated form (LPS $1435 / 1449)$. The penta-acylated form predominantly activates TLR4 mediated NF- $\kappa \mathrm{B}$ signaling pathway whereas tetra-acylated form promoted the production of anti-inflammatory proteins (e.g., Annexin A2 and Annexin A6) (Herath et al., 2016). 
Lipid-A portion of the LPS is found to activate host inflammatory response and disrupt bone remodeling. LPS of $P$. gingivalis 'paralyse' the gingival epithelial cells limiting the production of IL-8. This is called chemokine paralysis (Darveau, Belton, Reife, \& Lamont, 1998). LPS inhibits osteoblastic differentiation and mineralization hence preventing healing of the periodontal tissues (How et al., 2016).

Presence of circulating LPS promotes the production of metalloproteinases which is implicated in cardiac dysfunction (How et al., 2016). It also stimulates the production of thrombospondin-1, which stimulates the migration of monocytes (Gokyu et al., 2014). A recent fining by $\mathrm{Ci}$ et al. demonstrated the inhibitory effects of grape seed extract (proanthocyanidin) on P. gingivalis LPS (Ci, Chen, \& Ou, 2015). Tormentic acid, on the other hand, is reported to inhibit LPS-induced inflammatory response in human gingival fibroblast by inhibiting the production of IL-6 and IL-8 (Jian et al., 2015).

\subsubsection{Proteases}

P. gingivalis primarily produces two distinct families of proteases- cysteine proteinase family and serine proteinase. The cysteine-proteinases cleave polypeptides at C-terminal after arginine or lysine residue. Two major cysteine-proteases produced by $P$. gingivalis are, Gingipain-R and K. Further, there are two types of gingipain R, RgpA and RgpB. Gingipain R cleaves arginine while K cleaves lysine (Bostanci \& Belibasakis, 2012). These proteinases constitute $85 \%$ of the extracellular proteolytic activity of the $P$. gingivalis (de Diego et al., 2014). Rgp can degrade extracellular matrix, immunoglobulins, cytokines, 
etc. It is also crucial for the maturation of the fimbriae. Gingipain can degrade fibrinogen and heme proteins which may promote bleeding and increase the availability of heme protein for bacterial growth. They degrade antibacterial peptides like $\alpha$-defensin, complement factors. They reduce the expression of CD14 resulting a hyporesponsive macrophage. Proteases are involved in the degradation of collagen, activation host matrix metalloproteinases, inactivation of plasma proteinase inhibitors, cleavage of cell surface receptors and deregulation of the inflammation. They also act as an additive to the growth of A. actinomycetemcomitans and T. forsythia (How et al., 2016) (Mysak et al., 2014).

\subsubsection{Outer Membrane Protein}

Porphyromonas gingivalis possess two cell membrane layers- the outer membrane and the inner membrane. These layers differ from each other in structure as well as composition. These two layers are separated from each other with a peptidoglycan rich layer called as periplasm. The outer layer is asymmetrical in structure and is bi-layered comprising of lipopolysaccharide rich outer portion and a phospholipid-rich inner portion. The inner membrane is a phospholipid layer with proteins. The bacterial cell membrane acts as a selective barrier. Of the two outer membranes is supposed to contribute more towards inflammatory response as it is the more exposed part when compared of the two. It helps P. gingivalis interact with other periodontal microflora and upregulate $\mathrm{T}$ helper cells to produce IL- $\beta$ and IL-6 (Mysak et al., 2014) (How et al., 2016a). 


\subsubsection{Porphyromonas gingivalis Beyond Periodontitis}

In recent years there is emerging evidence that $P$. gingivalis is not merely limited to periodontal diseases. Further, that the relationship between periodontal diseases and systemic diseases is not unidirectional. This discovery of this bidirectional relationship has

fueled numerous studies in this direction. Porphyromonas gingivalis has been implicated in various diseases including cardiovascular diseases, atherosclerosis, cancer, Alzheimer's, etc. (Mysak et al., 2014)

Its involvement in various cancers in very interesting. With a rising number of cancer cases in recent times compounded with an almost ubiquitous presence of this organism demands immediate attention.

\subsubsection{Porphyromonas Gingivalis and Cancer}

Since the 1990s, there is accumulating evidence against Porphyromonas gingivalis as a mediator in the development of chronic diseases and oro-digestive cancers (Atanasova \& Yilmaz, 2014). Tezal et al. demonstrated the association between periodontitis and the incidence of cancer of the oral cavity, oropharynx, and larynx with the strength of association greatest in the oral cavity followed by oropharynx and larynx (Tezal et al., 2009). In a prospective study conducted on 405 pancreatic patients, it was found that patients with high levels of antibodies against Porphyromonas gingivalis ATCC 53978 were 2-fold more likely risk of pancreatic cancer than individuals lower levels of these 
antibodies (Michaud et al., 2013). In a prospective cohort study conducted on 361 incidents of pancreatic adenocarcinoma, Porphyromonas gingivalis increased the Odds Ratio of presence vs. absence to 1.16 (Fan et al., 2018).

Porphyromonas gingivalis can invade gingival squamous cell carcinoma. A relatively greater invasion was seen in the case with poorly differentiated cells (Katz, Onate, Pauley, Bhattacharyya, \& Cha, 2011). In a prospective study, Ahn et al. found oro-digestive cancer's mortality is related to periodontitis and Porphyromonas gingivalis (Ahn, Segers, \& Hayes, 2012). Porphyromonas gingivalis in the presence of human $\alpha$-defensins promoted cell proliferation in oral tumor cells (Hoppe et al., 2016). Porphyromonas gingivalis alters expression of the $\mathrm{B} 7-\mathrm{H} 1$ and $\mathrm{B} 7-\mathrm{DC}$ receptors in squamous carcinoma cells, which may help oral cancer cells from evading immune response (Groeger, Domann, Gonzales, Chakraborty, \& Meyle, 2011).

Porphyromonas gingivalis is capable of activating ERK1/2-Ets1, p38/HSP27, and PAR2/NF-kB pathways to induce proMMP9 expression. This proenzyme is later converted by gingipain, a protease produced by Porphyromonas gingivalis, which promotes invasion in oral squamous cell carcinoma (OSCC) cell lines (Inaba et al., 2014). It is shown to promote tumor growth by enhancing endothelial progenitor cell function and neovascularization through GroEL protein (Lin et al., 2015). It produces proteases like gingipain. Gingipain is found to affect the stability and function of SPINK6, a Kallikrein inhibitor. Gingipain promotes the activation of Kallikrein. Kallikrein is positively associated with tumor development and is clinically used as a tumor progression marker. 
This indicated a possible mechanistic relationship between periodontal disease and tumor progression(Plaza et al., 2016).

$\beta$-Catenin pathway has also been suggested as a possible pathway for the promoting proliferation in the epithelial cells by Porphyromonas gingivalis (Zhou et al., 2015). In a separate study, Porphyromonas gingivalis and Fusobacterium nucleatum were found to enhance tumorigenesis of oral epithelial cells through Toll-like receptors (Binder Gallimidi et al., 2015). However, a previous study contradicts these findings (Park, Yoon, Jeon, Ahn, \& Yoon, 2010). Ha et al. in a recent study pointed out the Porphyromonas gingivalis is capable of promoting epithelial-mesenchymal transition-like changes in oral squamous cell carcinoma (Ha et al., 2015). Further, they also found out that Porphyromonas gingivalis promoted invasiveness of OSCC via IL-8 and MMPs (Ha et al., 2016).

All these evidence pointed that Porphyromonas gingivalis might also play a role in the progression of esophageal squamous cell carcinoma. The first direct evidence of the role of Porphyromonas gingivalis in esophageal squamous cell carcinoma was published in a study by Gao et. al. In their study, they showed that Porphyromonas gingivalis preferentially invaded esophageal squamous cell csqarcinoma when compared to healthy tissue. Epidemiological data suggested that Porphyromonas gingivalis was positively associated with various clinicopathological factors including differentiation, metastasis and overall survival rate (Gao et al., 2016). This is a significant finding as for the first time Porphyromonas gingivalis was linked to the progression of ESCC and the patient survival rate. 


\subsection{Cyclins and CDKs}

\subsubsection{Introduction to Cell Cycle}

The cell cycle is the life story of cells. It comprises of stages through which the cell passes from one division to the next. A cell cycle beings after a cell has completed its division. Every new cell metabolizes, grows and develops. Throughout its life, it accumulates all of the necessary ingredients that are required for cell division. Once all of the ingredients are ready, the cell divides, and the cycle continues. Progression through the cell cycle is a highly regulated mechanism, and it is manned by key transition points which are called by checkpoints. The checkpoint allows or prohibits or passage into the next stage. These checkpoints make sure that the cell has acquired all of the necessary cellular components, and that all of the components are functional before allowing it to move onto the next stage. Any defect in these checkpoints can lead to unregulated cell growth which is seen in some cancers.

The cell cycle majorly composes of two phases; interphase and mitotic phase. Mitotic phase is the period of active cell division. Interphase precedes M phase and is a preparatory

phase. M phase includes the division of the nucleus, also called as Karyokinesis, and the division of cytoplasm, cytokinesis. 


\subsubsection{Interphase}

It is the longest period of the cell cycle, during this phase, DNA is synthesized, RNAs and proteins are produced, and energy reserves are built up. By convention interphase is divided into three sub-phases; Gap1 (G1) phase, Synthesis (S) phase, and Gap2 (G2) phase.

G1 phase the cell grows in size and the proteins necessary for cell division are synthesized. Near the end of the G1 phase, G1/S checkpoint makes sure that all of the necessary enzymes for the replication of DNA are present. After this checkpoint is passed, the cell is committed to dividing. Some cells before reaching G1/S checkpoint enter a G0 phase. It is a non-dividing phase of cell cycles. Cells in the G0 phase remain stable and maintain constant size. However, in certain conditions, they can re-enter the G1 phase.

After the G1 phase, the cell enters the $S$ phase (synthesis phase). In this phase the chromosomes duplicate. As a result at the end of this phase, each chromosome is composed of two chromatids.

After the S phase, the cell enters the G2 phase, where other necessary biochemical events take place. At the climax of the G2 phase, there is an critical checkpoint- G2/M checkpoint. The cell will pass through this checkpoint if and only if the cell is undamaged. The presence of any damaged DNA inhibits the activation of proteins that are necessary for mitosis. After G2/M checkpoint the cell is ready to divide and enters $M$ phase. However, in a cancerous 
cell, these checkpoints fail to check cell multiplication leading to uncontrolled multiplication

\subsubsection{M-phase}

M-phase is the part of the cell cycle where the cell separates and undergoes division. Mphase is divided into five stages; Prophase, Prometaphase, Metaphase, Anaphase, and Telophase (Pierce B.A, 2014).

\subsubsection{Cyclin E and CDK2}

In a normal cell, the progression through the cell cycle is a highly regulated process through which homeostasis in the cell number is maintained. Among other mechanisms, cell utilizes multiple checkpoints to control cell growth. These checkpoints are set up at various points throughout the cell cycle. These checkpoints regulate the passage of cell from one phase to the next. Cancer cells exhibit a dysregulation in this process. This may result in an increased number of cells and rapid tumor growth (Pierce B.A, 2014).

Cyclins and cyclin-dependent kinases act a check-points throughout the cell cycle. Cyclin proteins have two subunits, a catalytic subunit, and a regulatory subunit. The regulatory subunits are activated by Cyclin-dependent Kinases (CDKs). Once activated the catalytic part of cyclin protein becomes active and exhibits its downstream effects (Hwang \& Clurman, 2005). CDKs remains more or less constant throughout the cell cycle whereas 
the level of Cyclins fluctuates depending on the stage of the cell cycle. A preceding cyclin promotes the production of the cyclin next in line.

Cyclin $\mathrm{E}$ is one such cyclin protein. It acts as a gatekeeper and controls the transition of the cell from $\mathrm{G}_{1}$ phase to $\mathrm{S}$ phase of the cell cycle. $\mathrm{CDK} 2$ binds with Cyclin $\mathrm{E}$ to forms $\mathrm{A}$ CyclinE-CDK2 complex. Activated CyclinE-CDK2 complex phosphorylates Retinoblastoma $(\mathrm{Rb})$ to promote $\mathrm{G}_{1}$ progression. Hyperphosphorylated $\mathrm{Rb}$ promotes $\mathrm{E} 2 \mathrm{~F}$ transcription. This leads to the expression of genes that drive S-phase's initiation and progression (Siu, Rosner, \& Minella, 2012).

The periodicity in the activity of Cyclin E-CDK2 complex is a result from multiple factors including

- an abundance of Cyclin E levels,

- binding of Cip/Kip CDK inhibitors and,

- modification of CDK2 behavior by inhibiting and activating phosphorylation.

These multiple layers of control ensure proper regulation of Cyclin E activity. In contrast, CyclinE-CDK2 activity is often dysregulated in cancer cells, and this is likely to contribute to the development of cancer. It is proposed that activation of cyclin E expression in excess may be a product of dysfunctional regulatory mechanism rather than a mutation in Cyclin E itself (Hwang \& Clurman, 2005). 
Hence, there is a high probability that a more rapidly progressing tumor will express a greater amount of Cyclin E expression. In this rapidly progressing tumor higher cyclin $\mathrm{E}$ production will facilitate the cancer cell to quickly transition $G_{1}$ phase to $S$ phase of the cell cycle.

Cyclin-dependent Kinases (CDKs) are serine/threonine protein kinases. They elicit their enzymatic reaction with the help of a separate cyclin subunit. In addition to playing an essential role in cell division, they also play a key role in modulating transcription in response to extra and intracellular cues. Hence can be divided into two major subfamilies as dictated by the above properties. CDK1, 2, 4, and5 are related to cell cycle whereas CDKs 7, 8, 9, 11, and 20 belong to the transcription subfamily (Malumbres, 2014). 


\subsection{Apoptosis}

\subsubsection{A brief introduction to apoptosis}

The role of apoptosis in normal physiology is opposite to that of mitosis but has a complementary role in the development. Cancer is often seen where the cell cycle mechanism is out of control resulting in continuous proliferation, but it must be remembered that apoptosis plays a crucial role as well. It is often found that in most of the cancer cases the increased proliferative ability is compounded with a failure of apoptotic mechanisms.

Apoptosis is often referred to as programmed cell death. Apoptosis is a natural process that occurs during development and serves a homeostatic mechanism to maintain a proper number of cells. It sometimes also occurs as a form of defense mechanism. A variety of conditions can trigger apoptosis. Genetically determined events being one of the prime examples. Apart from its irradiation, drugs, steroids, etc. may also lead up to this event. At low doses, noxious stimuli like heat, hypoxia, anti-cancer drugs, etc. can induce apoptosis. However, these same stimuli at higher dosage produce necrosis. Apoptosis is an energydependent process. It is mediated through cysteine proteases called a Caspases. Activation of caspases initiates a chain of events that culminates into cell apoptosis. 


\subsubsection{Morphology}

During the process of apoptosis, the cell undergoes numerous changes. Cell shrinkage and pyknosis are perhaps the most easily witnessed phenomenon. Apoptotic cells grow smaller in size. The cytoplasm becomes dense, and all the organelles are tightly packed together. There is an extensive blebbing of the plasma membrane. This followed by karyorrhexis and separation of cell fragments into smaller apoptotic bodies. These apoptotic bodies contain densely packed organelles. The integrity of the organelles is well maintained in these bodies. These apoptotic bodies are usually then phagocytosed by the nearby macrophages. Macrophages that engulfs these apoptotic bodies are called as tangible body macrophages. Interestingly, though apoptosis involves macrophages, it is not an inflammatory process. This is because cell undergoing apoptosis do not release their cellular constituents into the surrounding, the remnants are quickly removed, and the engulfing cells do not produce any inflammatory cytokines (Kerr, Wyllie, \& Currie, 1972).

\subsubsection{Morphological Changes During Necrosis}

Necrosis is often associated with cell swelling as opposed to cell shrinkage as seen in the case of apoptosis. Necrotic cells form cytoplasmic vacuoles and are associated with distended endoplasmic reticulum and formation of cytoplasmic blebs. The mitochondria are often swollen or ruptured. Ribosomes are detached. There is a summary disruption of the membrane of the organelle and the cell. This results in spilling of the inner contents of 
the cells into the surrounding tissues. This triggers an inflammatory reaction (Majno \& Joris, 1995)

\subsubsection{Apoptosis versus Necrosis}

Necrosis is a toxic process and follows the energy-independent mode of death. Necrosis is an uncontrolled, and passive process. It usually affects a large field of cells either directly or indirectly. Apoptosis, on the other hand, is a much more controlled process. It is energy dependent and affects only a limited cluster of cells (Majno \& Joris, 1995).

During the process of apoptosis, there is an externalization of residue on the apoptotic cells which can be detected by Annexin V. A similar phenomenon also occurs in necrotic cells. Therefore, cells are usually labeled with membrane impermeable nuclei dye like propidium iodide. Propidium Iodide fails to label apoptotic cells because of membrane integrity of the apoptotic bodies. However, this is not the case with necrotic cells. Their disrupted cell membrane allows the Propidium Iodide to enter label the nuclear material (Elmore, 2007)

\subsubsection{Mechanism of Apoptosis}

\subsubsection{Intrinsic Pathway}

There are two main apoptotic pathways: the extrinsic and the intrinsic pathways. The intrinsic pathway is mediated by mitochondria and is regulated by the BCL-2 family. The 
$\mathrm{BCl}-2$ family consists of three subfamilies: proapoptotic $\mathrm{BH} 3$-only members, proapoptotic effector molecules (Bax and Bak), and antiapoptotic $\mathrm{BCl}-2$ family proteins. In a healthy cell, Bax/Bak keep a check on the antiapoptotic BCL2.

In the presence of an apoptotic stimulus, there is an upregulation of $\mathrm{BHC} 3$ protein. $\mathrm{BHC} 3$ protein in turns promotes the release of cytochrome $\mathrm{c}$ through Bak and Bax. Cytochrome along with Apaf-1 form an apoptosome. Binding of Cytochrome c to Apaf-1 replaces ADP with dATP. This complex recruits procaspase 9 which undergoes autocatalytic cleavage. The activated Caspase 9, in turn, activates Caspase 3.

The second group of apoptotic proteins called AIF, which are expressed at many later stages when the cell has committed itself to die is released from the mitochondria. After its release, the protein translocates itself to the nucleus of the cell where it causes the fragmentation and condensation of the DNA. Similar actions are produced by Endonuclease G and CAD protein. However, AIF and Endonuclease G function through a caspase-independent pathway whereas CAD is translocated inside the nucleus after it is cleaved by Caspase 3 (Elmore, 2007).

\subsubsection{Extrinsic Mechanism}

Extrinsic mechanism leads to the activation of a "Death receptor." They have a cysteinerich extracellular portion and 80 amino acids long intracellular component called as death domain (Ashkenazi \& Dixit, 1998). The death domain is responsible for transferring the death signal from outside the cell to its inside. TNF receptor is a classic example of a death 
receptor. On binding with TNF ligand, the TNF receptor is activated to bind with adapter protein Tumor Necrosis factor receptor type-1 associated protein with death domain protein (TRADD), which allows the recruitment of caspase 8 resulting in cell apoptosis (Elmore, 2007).

\subsubsection{A Gist of Caspase Activity}

Whether it be an extrinsic or intrinsic mechanism of apoptosis both of the process converges on the activation of Caspase. There are 13 different types of caspase molecules. They have been broadly grouped into executioner caspases and initiator caspases. Once the executioner caspases are activated by initiator caspase (Caspase-8, 9 and 10), they start degrading nuclear and cytoplasmic proteins. In apoptotic cells, caspase 3 activates CAD by cleaving ICAD. CAD then degrades the DNA within the nucleus and causes chromatin condensation. Caspase 3 cleaves Gelsolin protein. Cleaved gelsolin fragments, in turn, cleaves actin in a calcium-independent manner. This results in the disruption of the cytoskeleton, intracellular transport, cell division, etc (Elmore, 2007). 


\section{Hypothesis}

Porphyromonas gingivalis infection promotes cancer cell viability by enhancing cell proliferation, and reducing chemotherapy drug-induced apoptosis in ESCC. 


\section{MATERIALS AND METHODS}

\subsection{Bacteria}

ATCC Pg33277 was purchased from the American Type Culture Collection (Manassas, VA) and maintained as frozen stocks. $P$. gingivalis was grown in Gifu anaerobic medium (GAM; Nissui Pharmaceutical, Tokyo, Japan). P. gingivalis was grown under anaerobic conditions $\left(80 \% \mathrm{~N}_{2}, 10 \% \mathrm{H}_{2}\right.$, and $\left.10 \% \mathrm{CO}_{2}\right)$ at $37^{\circ} \mathrm{C}$ in a Coy Laboratories Anaerobic chamber (Grass Lake Charter Township, MI). Growth was monitored by tracking optical density at a wavelength of $600 \mathrm{~nm}$.

\subsection{Cells}

Human-derived esophageal squamous cell carcinoma cell line (EC9706; NE3; KYSE-30; KYSE-70) was maintained as a frozen stock. They were grown in RPMI 1640 (Gibco® RPMI 1640 Cat. No. 21870-076) supplemented with 10\% heat-inactivated Fetal Bovine serum (Atlanta Biologicals Cat No. S11150H), 1\% Penicillin (10,000 units/ml) and Streptomycin $(10,000 \mu \mathrm{g} / \mathrm{ml})$ (Gibco® Pen-Strep); 20mM HEPES (4-(2-Hydroxyethyl) piperazine-1-ethanesulfonic acid) buffer (Cellgro Cat. No. 25-060-CI), 20 mM sodium bicarbonate (Cellgro Cat. No. 25-035-CI), 1mM Sodium Pyruvate (Cellgro Cat. No. 
25000-CI), 50 $\mu \mathrm{M}$ 2-mercaptoethanol (Sigma Aldrich Cat No M7522) and MMP which was filtered and stored at $4{ }^{\circ} \mathrm{C}$. Cells were maintained at $37.5^{\circ} \mathrm{C}$ in a humidified aerobic incubator (Sheldon Manufacturing, Inc.) at $5 \% \mathrm{CO}_{2}$. When cells were incubated with Porphyromonas gingivalis penicillin was not added to the medium.

Different cell lines represented different differentiation levels. EC9706 is a poorlydifferentiated cell line. NE3 are immortalized esophageal epithelial cells that can serve as a cancer study model (Zeng et al., 2016). KYSE-30 is a well-differentiated ESCC cell which was obtained from a tumor in the middle third of the esophagus which extended beyond adventitia to invade surrounding structures. The patient did not receive any prior treatment. KYSE-70 is a poorly-differentiated cell line that was obtained from a tumor from the middle third of the esophagus. It extended into the muscularis propria of the esophagus. The patient did not receive any prior treatment (Shimada, Imamura, Wagata, Yamaguchi, \& Tobe, 1992).

\section{Chemotherapeutic Drugs}

Paclitaxel: Also known as Taxol, it was approved as a chemotherapeutic agent in 1992 by US FDA. It is isolated from Taxus brevifolia tree and belongs to the family of microtubule inhibitor. Hence it prevents the metaphase-anaphase transition. They are also believed to have anti-angiogenic effects (Khanna, Rosenberg, \& Vail, 2015). Paclitaxel for this project was sourced from Sigma Aldrich (Cat, No. T1912). 
Cisplatin: Also known as cisplatinum or cis-Diamminedichloroplatinum (II) is a chemotherapeutic agent. It was first synthesized by M. Peyrone in 1844 . Later in 1960 Rosenberg et al. observed its ability to inhibit division in E. coli. It was approved for use in 1978 by the FDA. It causes DNA damage and interferes with DNA repair leading to apoptosis. However, it commonly induces drug resistance and has several side effects (Dasari \& Tchounwou, 2014). Cisplatin for this project was sourced from Sigma Aldrich (Cat. No. 11343557).

5FU: 5 Flurouracili, a fluoropyrmidine, is used as the chemotherapeutic agent. It principally acts as thymidylate synthase inhibitor. By blocking the enzyme it prevents the synthesis of thymidine indirectly preventing DNA synthesis during S-phase (Focaccetti et al., 2015). 5FU for this project was sourced from Sigma Aldrich (Cat, No. F6627).

\subsection{Bacterial Invasion Assay}

P. gingivalis invasion into EC9706 cell line was detected using Leica TCS SP8 confocal laser scanning microscopy platform. $P$. gingivalis was labeled using Rabbit anti-Pg33277 primary antibody and AlexaFluor594 Goat anti-rabbit secondary antibody. Actin and DNA were labeled using ActinGreen ${ }^{\mathrm{TM}} 488$ ReadyProbes $^{\mathrm{TM}}$ Reagent, and DAPI proLong gold antifade reagent respectively. 


\subsection{MTT Proliferation Assay}

Vybrant MTT (3-(4,5-dimethylthiazol-2yl)-2,5-diphenyltetrazolium bromide) Cell Proliferation Assay Kit was utilized to determine the viability of EC9706 cell lines. An MTT assay involves the conversion of water-soluble MTT (3-(4,5-dimethylthiazol-2-yl)2,5-diphenyltetrazolium bromide) into an insoluble formazan salt. The formazan salt is then solubilized by SDS (sodium dodecyl sulphate), and the concentration is determined using optical density at 570nm. Viable cells can convert MTT to a formazan salt thereby indicates towards the number of cells.

\subsection{CCK-8 Proliferation Assay}

CCK-8, with 2-(2-methoxy-4-nitrophenyl)-3-(4-nitrophenyl)-5(2,4-disulphophenyl)-2Htetrazolium, monosodium salt, as an active component, allows more sensitive colorimetric assays for the determination of cell viability when compared with other tetrazolium salts. The CCK-8 test uses a water-soluble Tetrazolium salt that is reduced by dehydrogenase activity in the cell to produce a yellow colored formazan dye which is soluble in tissue culture media. The amount of formazan dye produced is directly proportional to the number

of living cells. The concentration is determined using optical density at 450nm ("Dojindo Cell Counting Kit 8” n.d.). 


\section{EdU Cell Cycle Imaging Assay}

Click-iT EdU Imaging kit from ThermoFisher scientific was utilized for cell cycle analysis. EdU (5-ethynyl-2'-deoxyuridine) is a nucleoside analog of thymidine and can be incorporated into the DNA during S-phase (DNA synthesis). The alkyne present in the EdU reacts with azide portion of Alexa Fluor dye through a copper catalyzed covalent reaction. Samples were fixed using $4 \%$ formaldehyde and then permeabilized with Triton X-100. Treatment with Triton X-100 allow the EdU to gain access to the DNA. Samples were incubated with EdU. Alexa Fluor azide 647 was utilized to measure the incorporated EdU using a Leica SP8 confocal inverted fluorescence microscope.

\subsection{Western Blot}

Samples were moved to on to the ice and washed with ice cold PBS. Cells were then lysed using RIPA buffer supplemented with EDTA, a phosphatase inhibitor, and a protease inhibitor. Lysate was homogenized by passing it through a sterile disposable insulin syringe. The lysate was centrifuged at $13,000 \mathrm{RPM}$ for $15 \mathrm{~min}$ at $4^{\circ} \mathrm{C}$. The pellet was discarded, and the lysate was aliquoted.

Protein concentration was estimated using Pierce BCA Protein Assay kit. Dilution of each sample $(1: 10)$ were incubate in a 96 well plate with $50 \mu$ l of reagent in a 1:1 ratio. Sample was incubated in dark for 1 hour. The optical density was then read at $562 \mathrm{~nm}$ in a spectrophotometer and the protein concentration is estimated 
Proteins are denatured at $70^{\circ} \mathrm{C}$ for 15 minutes along with Sample reducing buffer buffer and LDS Sample buffer. The protein samples were then separated based on their molecular weight using Novex NuPage ${ }^{\mathrm{TM}}$ 4-12\% Bis-Tris Gel and subsequently electrophoretically transferred onto a polyvinylidene difluoride membrane. Thus, the obtained membrane is blotted with $5 \%$ non-fat milk, washed with Tris-buffered solution supplemented with $0.1 \%$ Tween 20 (TBS-T) and then probed with the Primary antibody at concentration suggested by the manufacturer. The membrane is treated with HRP-conjugated secondary antibody. Chemiluminescent detection is performed, and the image will then be captured using ImageQuant $^{\mathrm{TM}}$ LAS 4000 mini (GE Healthcare).

\subsection{Transfection}

Transfection was performed to knockdown Cyclin $E$ and $C D K 2$ genes. siRNA was purchased from Dharmacon. Lipofectamine RNAiMAX Transfection Reagent in OptiMEM media is used to for transfection. Cell were transfected after reaching $60 \%$ confluency according to the protocol provided by the manufacturer. The accuracy of transfection was confirmed using western blot

\subsection{Statistical analysis:}

Data were using GraphPad PRISM ${ }^{\mathrm{TM}}$ (InStat v3.10 program; GraphPad Inc, San Diego California USA) software and appropriate tests were performed to establish statistical significance was set at $<0.05$. 
2.9 Human Subjects: No human subjects were used in the experiment. 


\section{RESULTS}

\subsection{P. gingivalis Can Invade EC-9706 Cells}

(A)

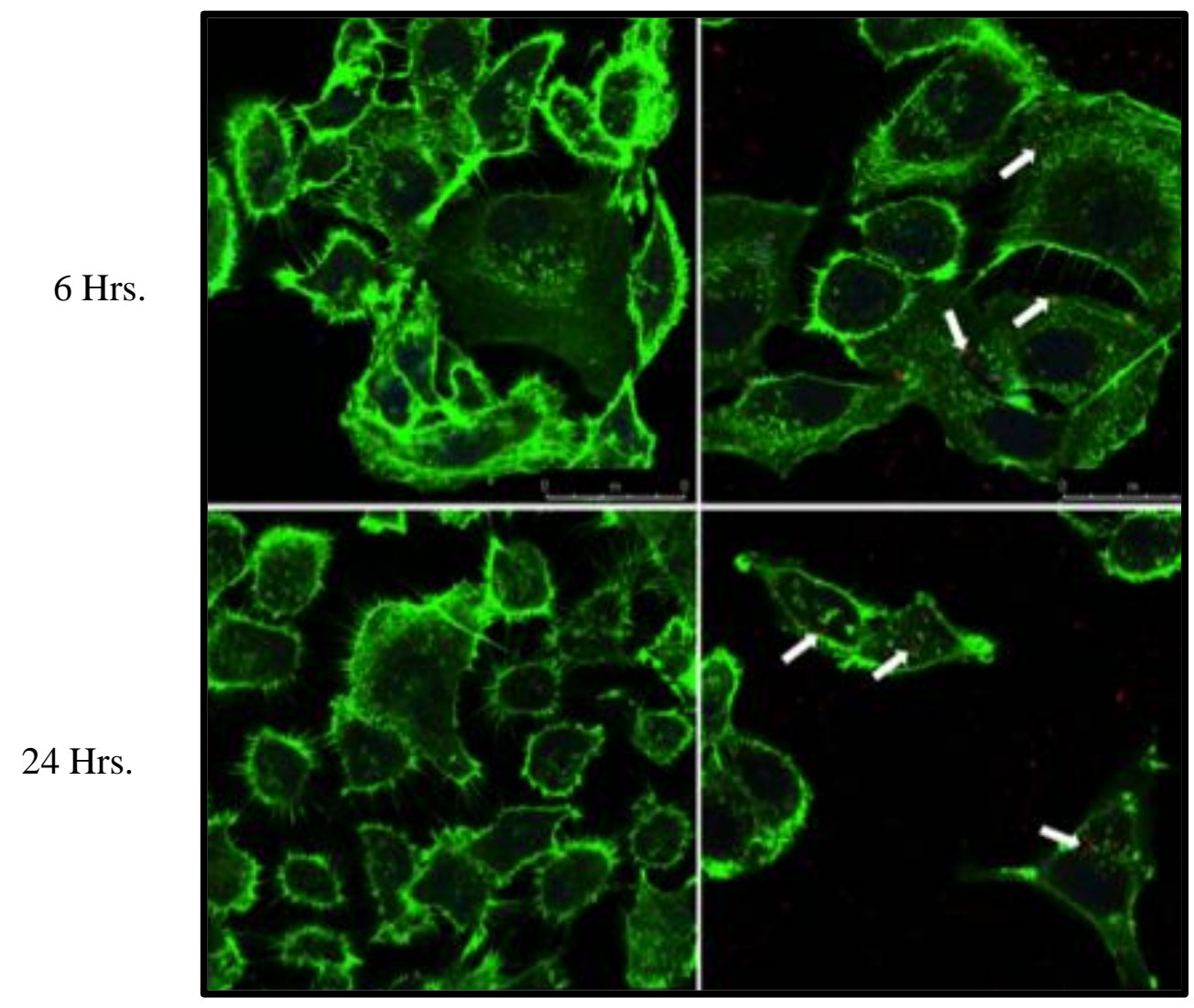

Figure 2: Confocal Image showing P. gingivalis invasion in (A) uninfected EC-9706 cells (control) and (B) EC-9706 infected with Porphyromonas gingivalis at two different time points of 6 hrs. and 24 hrs. Arrow points at P. gingivalis. The green color represents the actin cytoskeleton. The red color represents $P$. gingivalis. 


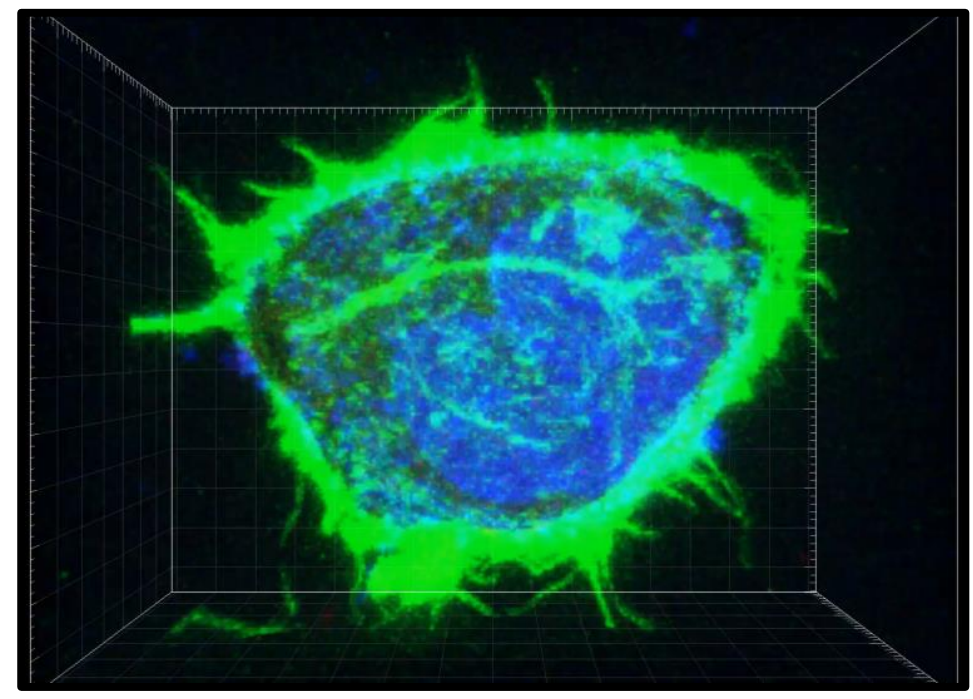

(A)

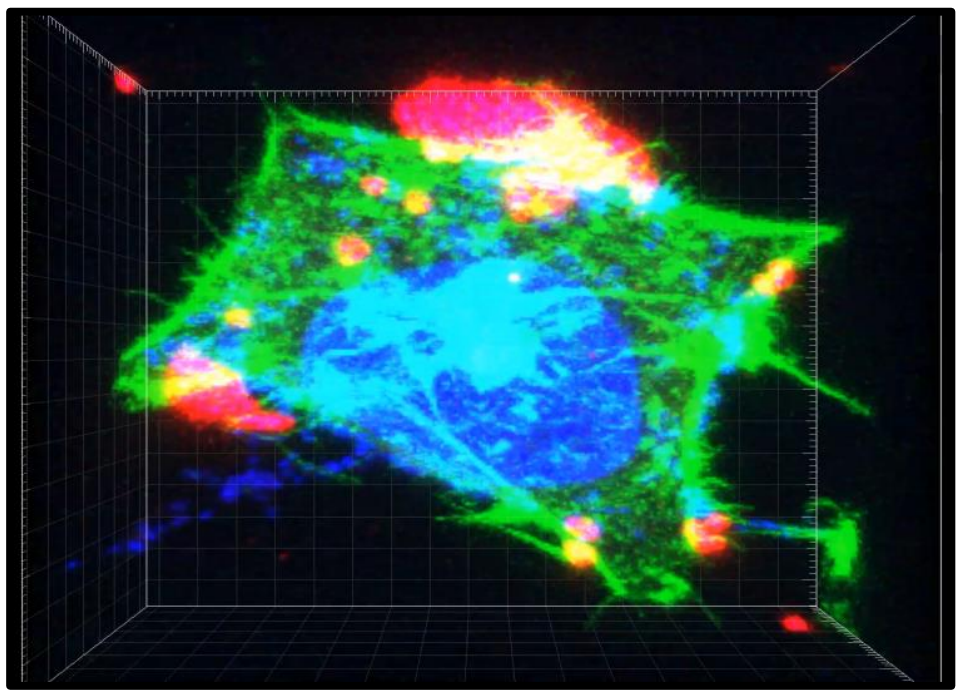

(B)

Figure 3: $3 D$ restructuring of the confocal image showing $P$. gingivalis invasion in $(A)$ uninfected EC-9706 cells (B) EC-9706 infected with P. gingivalis. The green color represents the actin cytoskeleton. The red color represents $P$. gingivalis. The green color represents the actin cytoskeleton. The blue represents the nuclei. The red color represents P. gingivalis 


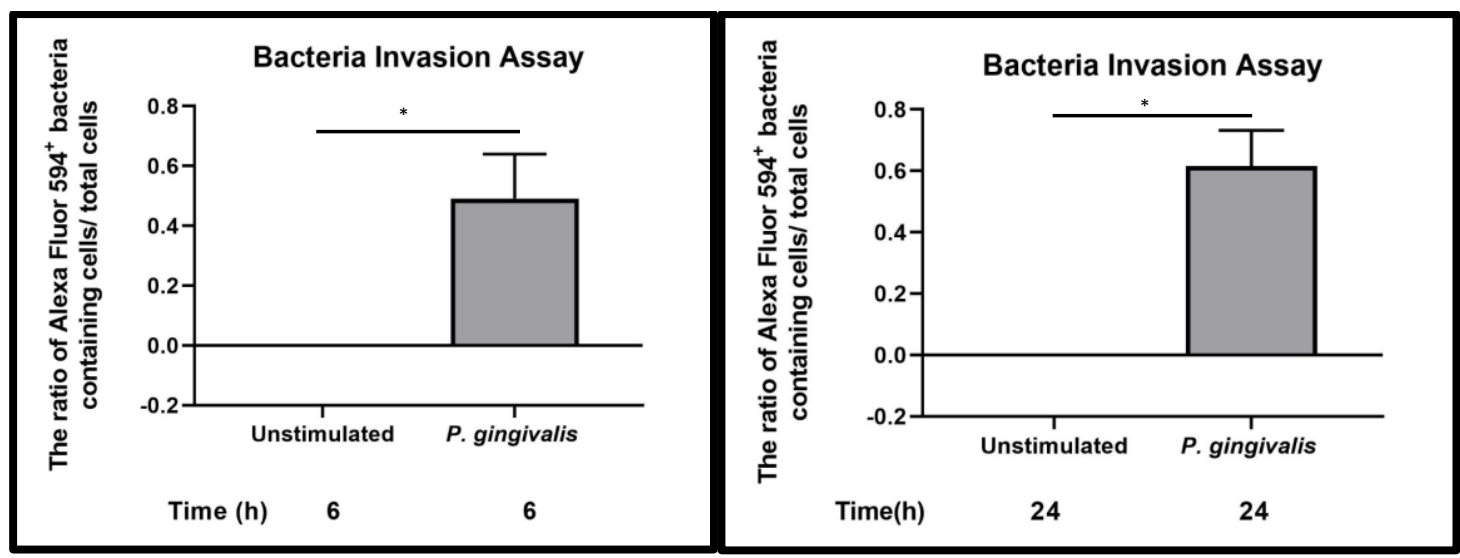

Figure 4: Graph showing the ratio of Alexa Fluor 594 positive bacteria (red) containing live cell to the total live cell present in uninfected/unstimulated EC-9706 cells and in EC9706 (0.5 x 105ell/well) infected with P. gingivalis ATCC 33277(MOI 10) at 6 hrs. and 24 hrs. Data presented with the mean \pm standard error.

To examine if $P$. gingivalis can invade ESCC cell in vitro we performed bacterial invasion assay. EC9706 (0.5 x 105/well) were incubated overnight in a 12 well plate. Afterwards, they were treated with $P$. gingivalis ATCC 33277 at MOI=10 for 8 hours. Cells were washed with PBS and fixed in $4 \%$ formaldehyde for $24 \mathrm{hrs}$. Cells were incubated with Rabbit Anti-P. gingivalis ATCC 33277 antibody (1:1000) overnight. Samples were incubated with Goat anti-rabbit Alexa Fluor 594 for 1 hour. Samples are then washed and are stained with ActinGreen ${ }^{\mathrm{TM}} 488$ ReadyProbes reagent for 30 minutes. Mounted on glass slides using ProLong Gold Antifade reagent with DAPI (4'6-diamidino-2-phenylindole) mounting medium prior to imaging with a Leica SP8 confocal inverted fluorescence microscope. Random 10 field of views were chosen. Cells with $P$. gingivalis in them were manually counted. Differences in the infected and uninfected group were determined by unpaired T-test (InStat version 3.10; GraphPad Inc, San Diego California USA). We found 
that $P$. gingivalis was successfully be able to reach inside the cell. Further, this was a time dependent phenomenon as more $P$. gingivalis was found within the cell at 24 hours when compared to 6 hours.

\subsection{P. gingivalis Promotes Proliferation in ESCC Cells}

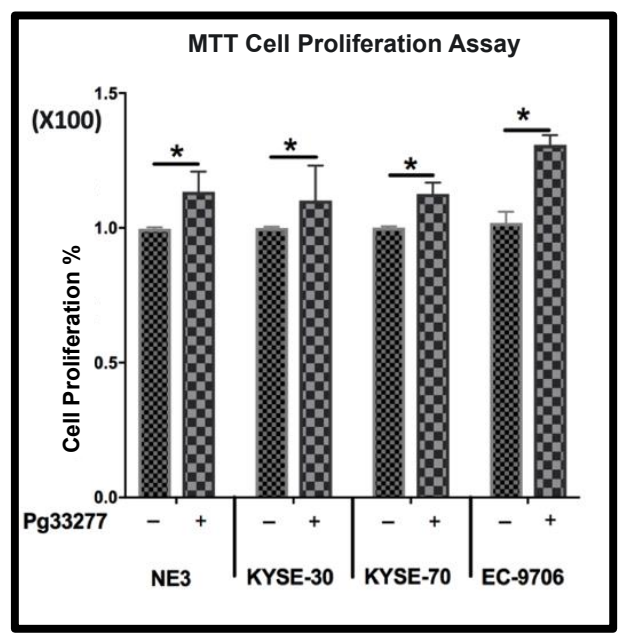

Figure 5: Graph showing the percentile of cell proliferation in P. gingivalis infected group when compared to uninfected group measured through MTT proliferation assay at $562 \mathrm{~nm}$. NE3, KYSE 30, KYSE 70 and EC9706 cell lines (5000 cell/well) were infected by Porphyromonas gingivalis ATCC 33277 (MOI 10) Data are presented as the mean \pm standard error of three individual experiments. Data are presented as the mean \pm standard error of three individual experiments.

To examine if $P$. gingivalis can promote proliferation in ESCC cells we performed an MTT proliferation assay. NE3, KYSE-30, KYSE-70 and EC-9706 (5000 cells/well) cell and incubated them overnight in a 96-well plate. They were treated with Porphyromonas 
gingivalis ATCC 33277 at MOI=10 for 48 hrs. Vybrant ${ }^{\mathrm{TM}}$ MTT Cell Proliferation Assay Kit was utilized to determine the viability of ESCC cell lines. MTT from the kit was added and the cells were incubated for 4 hours, followed by another 4 hours of incubation with SDS-HCl solution. Optical Density was measured at 562nm using spectrophotometer. Differences in the infected and uninfected group were determined by unpaired T-test (InStat version 3.10; GraphPad Inc, San Diego, California, USA). We found that Porphyromonas gingivalis ATCC 33277 significantantly increased proliferation in NE3, KYSE-30 , KYSE-70 and EC-9706 cell lines

\subsection{P. gingivalis Cannot Convert Tetrazolium Salts into Formazan Except at High}

\section{Concentrations}

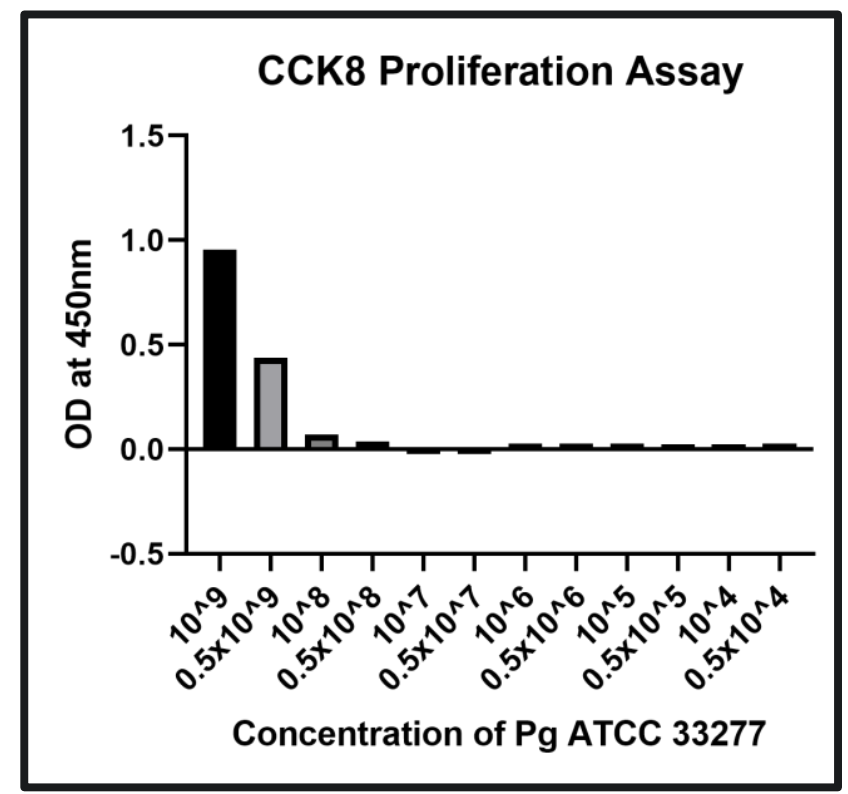

Figure 6: Graph showing the results for CCK8 proliferation assay at $450 \mathrm{~nm}$ for various concentration of $P$. gingivalis ATCC 33277. 
To examine if Porphyromonas gingivalis can by itself influence a Tetrazolium salt-based proliferation assay we utilized different concentrations Porphyromonas gingivalis and subjected it to CCK-8 proliferation assay. Porphyromonas gingivalis ATCC 33277 was added to 96 well plate in different concentrations. CCK-8 reagent $(10 \mu \mathrm{l})$ was added to the sample. The plate was incubated for 4 hours after which it was read at $450 \mathrm{~nm}$ using a spectrophotometer. The graph plotted using the optical density values obtained from the assay (InStat version 3.10; GraphPad Inc, San Diego, California, USA). Statistical analysis could not be performed due to the absence of replicates. This experiment was performed as a measure of added control. We utilized optical density as a measure because of the ease of translatability to other experiments.

\subsection{P. gingivalis Promotes Passage of ESCC Cells to S-Phases}

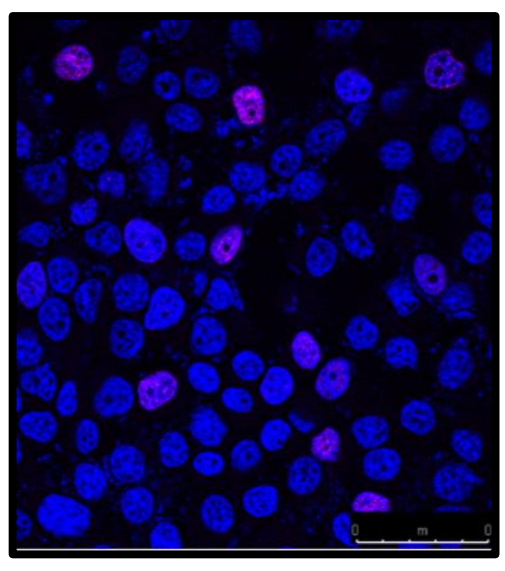

(A)

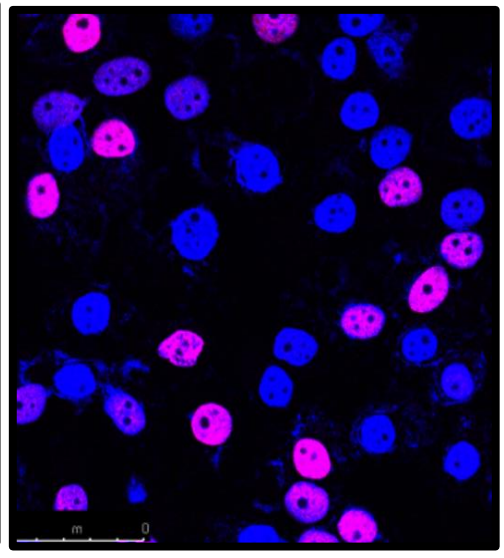

(B)

Figure 7: Confocal image showing (A) Uninfected/unstimulated EC-9706 cell nuclei (control) and (B) EC-9706 infected with Porphyromonas gingivalis. The blue of the nuclei is due to DAPI. The presence of pink in nuclei show EdU positive nuclei (Alexa Fluor 647) representing nuclei in S-phase 


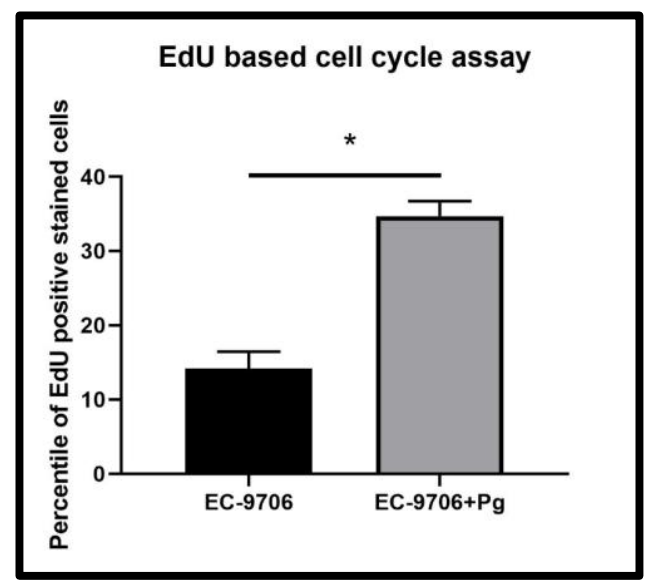

Figure 8: Graph showing the percentile of EdU positive (Alexa Fluor 647 positive) stained cells (A) Uninfected/unstimulated EC-9706 cells $\left(10^{5}\right.$ cell/well) (control) and (B) EC-9706 (10 cell/well) infected with Porphyromonas gingivalis ATCC 33277 (MOI 10). Data presented with the mean \pm standard error.

To examine how Porphyromonas gingivalis promotes cell proliferation we decided to perform an EdU based cell cycle assay using Click IT EdU Imaging kit by ThermoFisher. EC-9706 ( $1 \times 10^{5}$ cells/well) cell incubated overnight in a 12 well plate. EC-9706 was infected with Porphyromonas gingivalis ATCC 33277 at MOI 10 and was incubated for $20 \mathrm{hrs.} 10 \mu \mathrm{M}$ Edu was added and was incubated for another 4 hours. Cells were fixed using $4 \%$ formaldehyde for 24 hrs. Fixative agent was removed and cell were permeabilized with TritonX-100 for 30 minutes. Detergent was removed and Click-IT Alexa Fluor ${ }^{\mathrm{TM}}$ EdU buffer was added and incubated in dark for 30 minutes. Imaging was done using a Leica SP8 confocal inverted fluorescence microscope. Differences in the infected and uninfected group were determined by unpaired T-test (InStat version 3.10; GraphPad Inc, San Diego, California, USA). We found that Porphyromonas gingivalis promoted S-phase transition in EC-9706 cell line 


\subsection{Infection of $P$. gingivalis Differentially Alters the Activity of ESCC Cells}

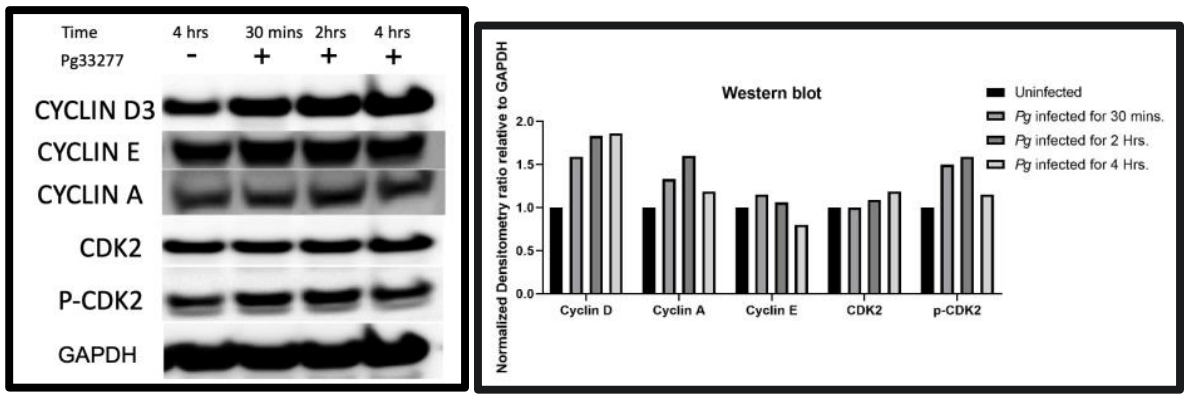

(A)

(B)

Figure 9: (A) Western blot showing Cyclins and CDK levels in P. gingivalis ATCC 33277(MOI 10) treated EC-9706 (10 cell/well) at time points 30mins, 2hrs. and 4hrs; (B)

A graph showing Cyclins and CDK levels in P. gingivalis ATCC 33277(MOI 10) treated EC-9706 (106 cell/well $)$ at time points 30mins, $2 \mathrm{hrs.}$ and $4 \mathrm{hrs.}$

EC-9706 cells $\left(1 \times 10^{6}\right.$ cells/well $)$ were seed into a 6-well plate and were incubated overnight. Samples were treated with P. gingivalis ATCC 33277 (MOI 10) for 30 minutes, 2 hours and 4 hours. The uninfected group ( 4 hours) served as a control for this experiment Sample were lysed using RIPA buffer (5 mM EDTA; SIGMA proteinase inhibitor cocktail; SIGMA phosphatase cocktail 2 and 3 and PMSF). and protein was homogenized using a fine bore sterile insulin syringe. Gel electrophoresis was utilized to seperate the proteins based on their molecular weight. Proteins were then transferred to a PVDF membrane and was read using suitable antibodies on ImageQuant ${ }^{\mathrm{TM}}$ LAS 4000 mini (GE Healthcare). Statistical analysis could not be performed due to the absence of replicates. 


\subsection{Proliferative Effect of $P$. gingivalis Was Nullified When $C D K 2$ gene Was Knocked}

\section{Down}

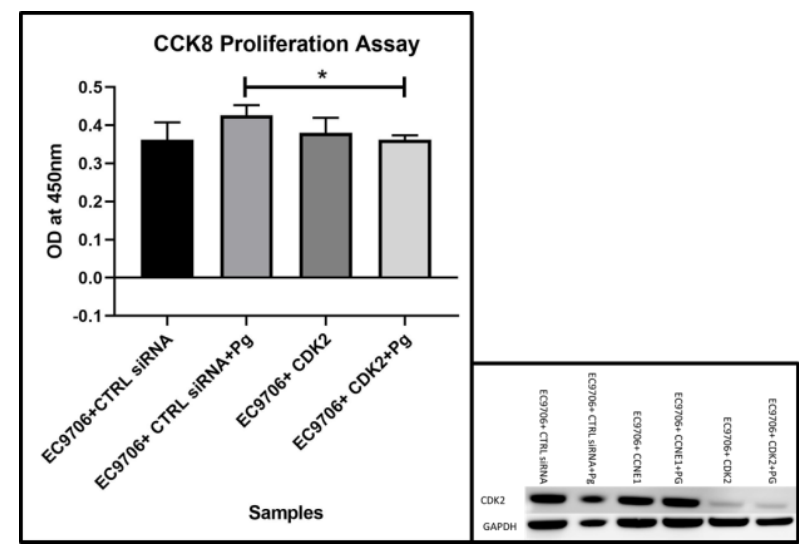

Figure 10: Graph showing the result of CCK8 proliferation assay at $450 \mathrm{~nm}$ for $P$. gingivalis ATCC 33277 (MOI 10) treated, CDK2 knocked down EC9706 cells. Data presented with the mean \pm standard error. Values are calculated by subtracting $O D 450$ nm - OD 450 nm of media blank. Western Blot showing the expression of CDK2 protein in CDK2 knockdown sample

We wanted to examine if CDK2 protein was involved in $P$. gingivalis mediated cell proliferation in ESCC cells. Hence, we conducted a transfection assay to knockdown CDK2 gene to decrease CDK2 production. EC9706 cells $\left(7.5 \times 10^{5}\right.$ cells/well) were seeded and were incubated overnight. Transfection was performed to knockdown $C D K 2$ using siRNA was purchased from Dharmacon. Lipofectamine RNAiMAX Transfection Reagent in OptiMEM media is used to for transfection. After $8 \mathrm{hrs}$. the cells were infected with Porphyromonas gingivalis (MOI=10:1) for 72 hrs. Medium was replaced every 24 hours 
after transfection. After 72 hours CCK-8 Proliferation assay was utilized to estimate cell proliferation. Cells were incubated with CCK-8 reagent for 4 hours in dark. Optical density was measured at $450 \mathrm{~nm}$ using a spectrophotometer. Accuracy of the transfection was measured using western blot. Differences in the infected and uninfected group were determined by one-way ANOVA test with a post hoc Tuckey test (InStat version 3.10; GraphPad Inc, San Diego, California, USA). We found that $P$. gingivalis could not promote cell proliferation in EC-9706 cells if $C D K 2$ gene was knockdown, when compared to its control group.

3.7 Proliferative effect of $\boldsymbol{P}$. gingivalis was nullified when $C y c l i n E$ gene was knocked down

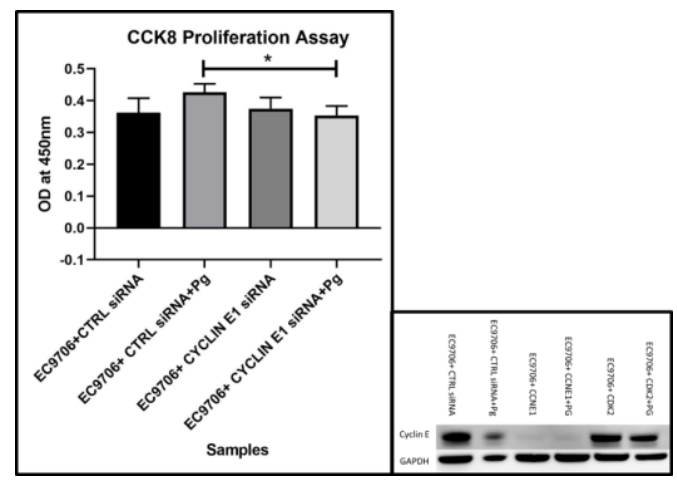

Figure 11: Graph showing the result of CCK8 proliferation assay at $450 \mathrm{~nm}$ for $P$. gingivalis ATCC 33277 (MOI 10) treated, Cyclin E knocked down EC9706 cells. Data presented with the mean \pm standard error. Values are calculated by subtracting OD 450nm - OD 450nm of media blank. Western Blot showing the expression of Cyclin E protein in Cyclin E knockdown sample 
We wanted to examine if Cyclin E protein was involved in $P$. gingivalis mediated cell proliferation in ESCC cells. Hence, we conducted a transfection assay to knockdown Cyclin E gene to almost eliminate Cyclin E production. EC9706 cells $\left(7.5 \times 10^{5}\right.$ cells/well) were seeded and were incubated overnight. Transfection was performed to knockdown CDK2 using siRNA was purchased from Dharmacon. Lipofectamine RNAiMAX Transfection Reagent in OptiMEM media is used to for transfection. After 8 hrs. the cells were Infected with Porphyromonas gingivalis ATCC33277 (MOI= 10:1) for $72 \mathrm{hrs}$. Medium was replaced every 24 hours after transfection. CCK-8 Proliferation assay was utilized to estimate cell proliferation. Cells were incubated with CCK-8 reagent for 4 hours in dark. Optical density was measured at $450 \mathrm{~nm}$ using a spectrophotometer. Accuracy of the transfection was measured using western blot. Differences in the infected and uninfected group were determined by one-way ANOVA test with a post hoc Tuckey test (InStat version 3.10; GraphPad Inc, San Diego, California, USA). We found that $P$. gingivalis could not promote cell proliferation in EC-9706 cells if Cyclin E gene was knockdown, when compared to its control group. 
3.8 Infection of $P$. gingivalis induces apoptosis resistance in EC-9706 upon treatment with different chemotherapy drugs

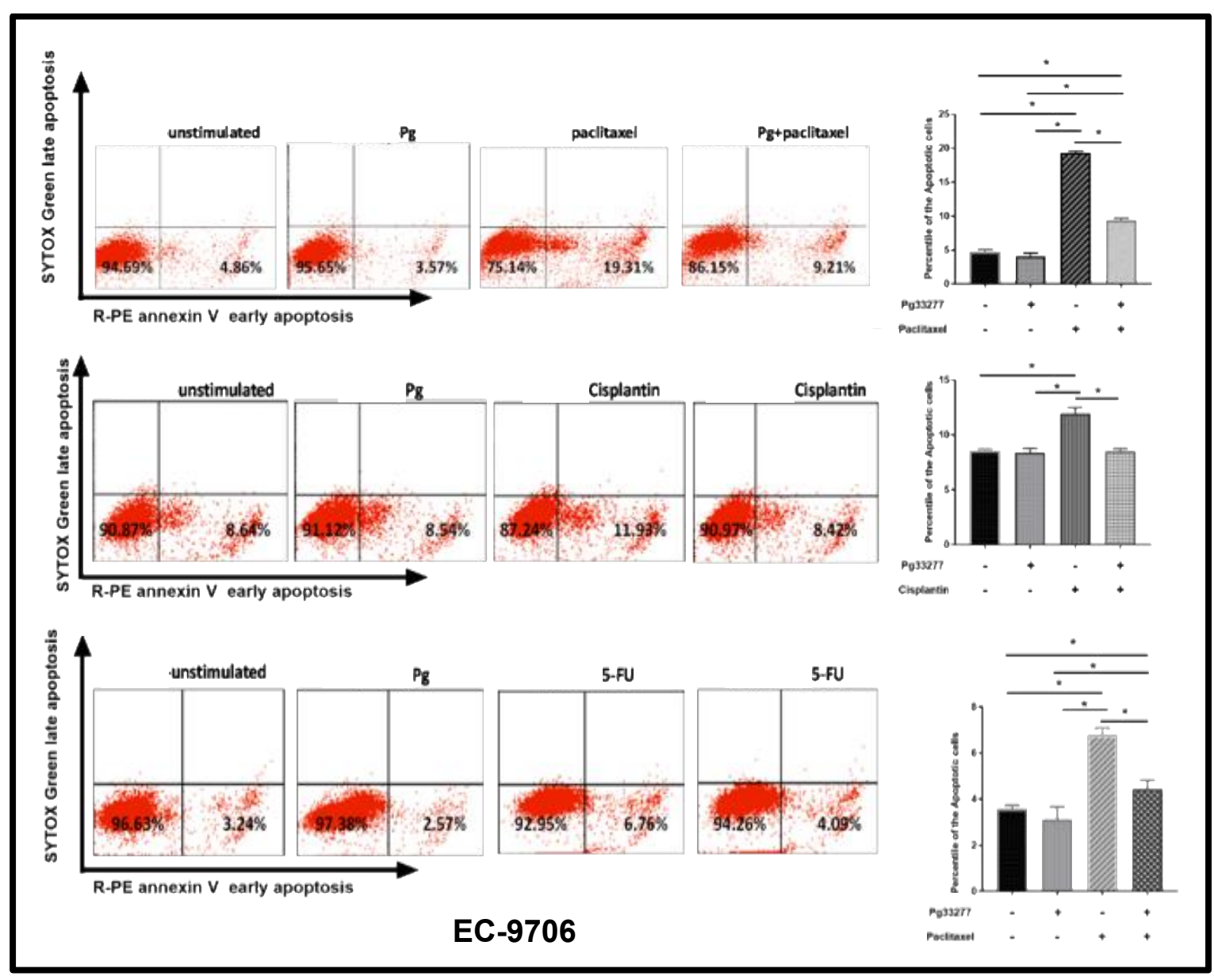

Figure 12: Image showing the results of flow cytometry in EC9706 on treatment with neoadjuvant drugs (Paclitaxel $=1 \mu M$, Cisplatin $=4 \mu M, 5-F U=2.5 \mu m$ ) in P. gingivalis ATCC 33277 (MOI 10) infected samples. Graphical representation of the flowcytometry Data are presented as the mean \pm standard error of three individual experiments.

We wanted to examine if $P$. gingivalis can promote apoptosis resistance in chemotherapy drug treated ESCC cells. Esophageal squamous carcinoma cells (EC-9706) were treated 
with $P$. gingivalis ATCC 33277 (MOI=10) for 24 hours followed by treatment with different chemotherapeutic agents (Paclitaxel, Cisplatin, 5-FU). Unstimulated group, Porphyromonas gingivalis treated only group and Chemotherapeutic treated only group served as controls for this experiment (Paclitaxel $=1 \mu \mathrm{M}$, Cisplatin $=4 \mu \mathrm{M}, 5-\mathrm{FU}=2.5 \mu \mathrm{m})$. Flow cytometry was utilized to measure the total number of apoptotic cells using Annexin $\mathrm{V}$ and Propidium Iodide as a marker. Data was quantified and is graphed as a percentile of apoptotic cells. Differences in the infected and uninfected group were determined by oneway ANOVA test with a post hoc Tuckey test (InStat version 3.10; GraphPad Inc, San Diego, California, USA). We found that in all the groups $P$. gingivalis promoted apoptosis resistance in EC-9706 cells. Apart from this we also observed difference between other sample of the group which is discussed in detail in the discussion section. 
3.9 Infection of $P$. gingivalis induces apoptosis resistance in different esophageal squamous cell carcinoma cells upon the treatment of paclitaxel

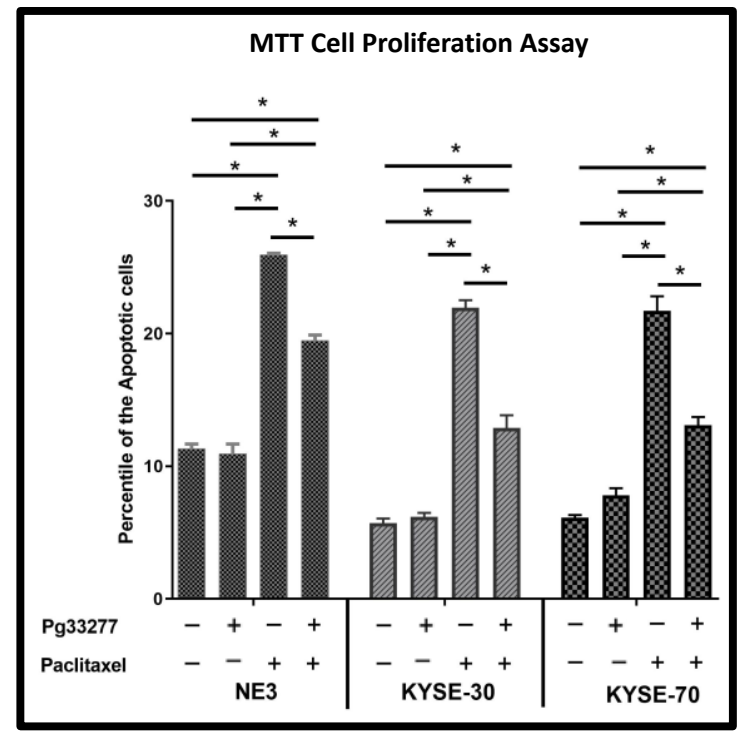

Figure 13: Graph showing the apoptosis resistance in NE3 KYSE-30 and KYSE-70 on treatment with neoadjuvant drugs Paclitaxel (1 $\mu$ m) in P. gingivalis ATCC 33277 (MOI 10) infected samples. Data are presented as the mean \pm standard error of three individual experiments.

ESCC cells (NE3, KYSE-30, KYSE-70) were treated with $P$. gingivalis for 24 hours followed by treatment with a chemotherapeutic agent (Paclitaxel). Unstimulated group, Porphyromonas gingivalis treated only group, and Chemotherapeutic treated only group served as a control for this experiment. MTT colorimetric assay was utilized to measure the total number of viable cells. Data was quantified and is graphed as a percentile of apoptotic cells. Differences in the infected and uninfected group were determined by one- 
way ANOVA test with a post hoc Tuckey test (InStat version 3.10; GraphPad Inc, San Diego, California, USA). We found that in all the groups $P$. gingivalis promoted apoptosis resistance in against Paclitaxel. Apart from this we also observed difference between other sample of the group which is discussed in detail in the discussion section.

\subsection{Infection of $P$. gingivalis and caspase 3 activity}

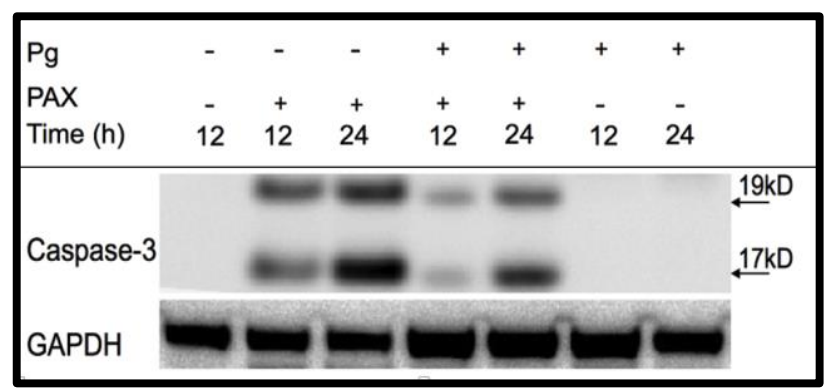

Figure 14: Western blot showing the Caspase 3 activity in P. gingivalis ATCC 33277 (MOI 10) infected EC9706 cells $\left(10^{6}\right.$ cells/well) at time points $12 \mathrm{hrs.}$ and $24 \mathrm{hrs.}$

To examine if $P$. gingivalis can affect caspase 3 production in ESCC cell we looked at the Caspase 3 protein levels under different treatments time points using western blot. EC9706 cells were treated with $P$ gingivalis for 12 - and 24 -hour time periods. The uninfected group served as a control for this experiment. Western blot was utilized to measure the changes in Caspase-3 levels. Sample were lysed using RIPA buffer (5 mM EDTA; SIGMA proteinase inhibitor cocktail; SIGMA phosphatase cocktail 2 and 3 and PMSF). and protein was homogenized using a fine bore sterile insulin syringe. Gel electrophoresis was utilized to separate the proteins based on their molecular weight. Proteins were then transferred to 
a PVDF membrane and was read using suitable antibodies on ImageQuant ${ }^{\mathrm{TM}}$ LAS 4000 mini (GE Healthcare). Statistical analysis could not be performed due to the absence of replicates. 


\section{DISCUSSION}

Previous studies have shown that $P$. gingivalis preferentially invade oral squamous cell carcinoma cells when compared to surrounding tissue. $P$. gingivalis promotes proliferation and epithelium-to-mesenchyme transition (EMT) in OSCC. It implies that $P$. gingivalis has the potential to transform OSCC to a more aggressive variety. Since the oral mucosa and the proximal part of esophageal lining are similar, it is entirely plausible that $P$. gingivalis can produce similar effects in ESCC. Porphyromonas gingivalis was found in the distant tissue of gastrointestinal-tract like colon and stomach tissue. Hence, more proximal tissue, like the esophagus, to the natural niche of Porphyromonas gingivalis is more likely to be infected.

In their study, Gao et al. showed that $P$. gingivalis preferentially localized itself in the cancerous tissue when compared to surrounding normal and dysplastic tissue. The study showed a positive correlation between $P$. gingivalis and poor survival rate. However, this study failed to explain why patients who are positive for $P$. gingivalis have poorer survival rates (Khanna, Rosenberg, \& Vail, 2015).

In our first experiment, we utilized EC9706, an ESCC cell line, to see if Porphyromonas

gingivalis retains its invasive capabilities in vitro. We chose P. gingivalis ATCC 33277 in 
this project, because in Gao et al. study the $P$. gingivalis antibody that was used on the esophageal tissue, was directed against $P$. gingivalis ATCC 33277. We set up the experiment at two different time points one at 6 hours and another at 24 hours. We planned to examine if Porphyromonas gingivalis invasion was time dependent. Our results show that Porphyromonas gingivalis was able to successfully invade EC9706 cells in vitro. Statistical analysis showed that Porphyromonas gingivalis invaded the cells in a timedependent manner with a 24 hours cell group showing higher invasiveness when compared to 6 hours group. We confirmed the invasion of EC9706 by Porphyromonas gingivalis by the $3 \mathrm{D}$ rendering of the obtained images. However, it must be noted that mere the presence of bacterium within the cell does not confirm active invasion. Further, experiments are needed to determine that if $P$. gingivalis invaded these cells or were engulfed by the process of phagocytosis. A $P$. gingivalis mutant with a defective $\Delta$ fimA gene can be used as a control for this experiment to show active invasion process. Fimbriae have been shown to critical for $P$. gingivalis. We expect that $\Delta$ fimA mutant will show sub-par invasiveness.

After confirming that Porphyromonas gingivalis can invade EC 9706 cells in vitro we went ahead to set up MTT proliferation assay to see if Porphyromonas gingivalis promotes proliferation of ESCC cells. We preferred using MTT proliferation assay over CCK-8 proliferation assay as it is less sensitive and requires a significant change to register a difference. By using this assay, we hoped to achieve more reliable results. In this experiment, we utilized 4 different cell lines of ESCC namely any NE3, KYSE30, KYSE70, and EC9706. The rationale behind using different cell lines was to see if the proliferative ability of Porphyromonas gingivalis is true across multiple cell lines. These 
cell lines are of different differentiation level. By utilizing different cell lines, we aimed to mimic real-life scenario. We infected half of the cells with Porphyromonas gingivalis ATCC 33277 while the other half remained uninfected and served as the control for the experiment. We found that Porphyromonas gingivalis infected ESCC cells and showed a significant increase in proliferation. This experiment shows that Porphyromonas gingivalis promotes proliferation of ESCC cells and this proliferative potential is true for multiple ESCC cell lines. However, it is be noted that this experiment did not have a control for a Gram-negative anaerobic bacterium. Further experiments are needed to done to see if this phenomenon is exclusive to $P$. gingivalis. These experiments are important as there is an emerging evidence that Fusobacterium nucleatum, a Gram-negative periodontal pathogen, can promote tumorigenesis through cell proliferation in colorectal cancer and OSCC (Binder Gallimidi et al., 2015; Mima et al., 2016; Shang \& Liu, 2018).

MTT (3-(4,5-dimethylthiazol-2yl)-2,5-diphenyltetrazolium bromide) Proliferation Assay is a tetrazolium-based assay. It relies on the conversion of the tetrazolium salt into insoluble purple colored formazan. This reaction relies on an NADPH dependent oxidoreductase enzyme. It is often used to determine cell proliferation. Since it is a quick and reliable method we decided to measure if $P$. gingivalis induced proliferation of ESCC cells.

However, we did not find any study that showed that if Porphyromonas gingivalis on its own can reduce tetrazolium salt to formazan. In case Porphyromonas gingivalis did have this ability, it would have produced overestimation of the number of cell in Porphyromonas gingivalis infected group. Hence, to determine if Porphyromonas gingivalis can 
significantly affect the results, we measured the ability of Porphyromonas gingivalis to convert tetrazolium to formazan. We used a more sensitive CCK-8 assay for this procedure. Unlike MTT Proliferation assay CCK-8 is faster and more sensitive. We used this assay instead of MTT proliferation assay to record even a minimalistic change. Based on our understanding of Tetrazolium salts and Porphyromonas gingivalis we expected Porphyromonas gingivalis to reduce Tetrazolium salts to formazan salt. We found that Porphyromonas gingivalis has a minimal capability of converting tetrazolium salt to formazan. At a lower concentration of $10^{5}$ cell, it produced no detectable change. Hence, the ability of Porphyromonas gingivalis to convert tetrazolium to formazan could have affected the results of the MTT proliferation assay. Further, it is to be noted that at higher concentration the sample appeared very cloudy which might have contributed to a sudden increase in optical density at higher values. This experiment served as an added control.

Next, we wanted to see how Porphyromonas gingivalis promoted proliferation. We decided to look at cell cycle in general, and S-phase in particular. S-phase or the synthesis phase of cell cycle is when the DNA replicates itself. Thus, it marks the commitment of the cell to divide. For this experiment, we used Click IT EdU Imaging kit by ThermoFisher. We chose this test over well-established BrdU because of the three advantages that EdU offered a) simplicity b) reliability and c) lower complexity. We labeled uninfected EC9706 cells and Porphyromonas gingivalis infected EC9706 cells with EdU to see the effects of Porphyromonas gingivalis on the phases of the cell cycle. During the S-phase of the cell cycle when the DNA duplicates, it allows the substitution of EdU into the DNA. Once incorporated it can be seen AlexaFluor 647. Cells in other phases of cell cycle do not allow 
this addition due to the inaccessibility of DNA to EdU molecule. The final image shows unstained or EdU negative nuclei as blue due to DAPI while EdU positive nuclei show in pink color. Our results showed that Porphyromonas gingivalis significantly promotes $\mathrm{S}$ phase in ESCC cells when compared to the uninfected control group.

Next, we infected EC9706 cells with Porphyromonas gingivalis ATCC 33277at an MOI 10 at 3 different time points; 30 minutes, 2 hours, and 4 hours. For this experiment, we chose early time points to early influences of $P$. gingivalis on cell cycle. After which we ran a western blot of all 4 samples ( 3 infected groups plus1 controlled) to look at different cyclins and CDK protein levels. We chose to look at different cyclin and CDK proteins to have a better understand the early influences of $P$. gingivalis invasion into the cell which would not have been possible if we would have limited ourselves to S-phase related proteins. We observed a general upward trend in all the cyclins and CDK proteins. However, as it was a single blot and there were no replicates, we could not perform any statistical comparison. Thus, we cannot be conclusive in this regard.

Based on our previous results, we expected to see a marked rise in cyclin E levels because Cyclin $\mathrm{E}$ is an important marker for S-phase. However, our results were not in line with our expectations. Though there was an increase in Cyclin D levels; levels of Cyclin E were more or less constant. In addition, we observed an increase in Cyclin A levels both of which are produced in S-phase after cell crosses G1/S phase guarded by Cyclin E. This anomaly can be explained by an increased productions p-CDK2. We believe that higher levels of the p-CDK2 push for increased in S-phase in spite of minimal changes in Cyclin E. We 
speculate that the rise in p-CDK can be due to Cyclin A2 or loss of Cip/Kip CDK inhibitor. Another possibility can be that Cyclin E may peak at a different time point.

Based on our previous results we speculated that Porphyromonas gingivalis promotes proliferation in ESCC cell line through Cyclin E-CDK2 mediated pathway. To confirm this, we performed transfection assay. In the first part of our experiment, we knocked down the CDK2 gene in the EC9706 cell line. After which we infected it with Porphyromonas gingivalis. We found that after $C D K 2$ gene was knocked down Porphyromonas gingivalis was not able to promote proliferation in EC9706 cells. We repeated this experiment by knocking down Cyclin E to find similar results. We conclude that Porphyromonas gingivalis promotes proliferation in EC9706 cell line through Cyclin E-CDK2 mediated pathway. We think that by knocking down Cyclin $E$ and $C D K 2$ we prevented the formation Cyclin E-CDK2 complex which might have been playing a key role in Porphyromonas gingivalis induced proliferation. Another interesting observation was the knockdown samples a showed similar growth rate as an uninfected ESCC cell.

In the second part of our experiment, we wanted to see if Porphyromonas gingivalis can promote apoptosis resistance in chemotherapeutically treated ESCC cells. To examine the apoptosis resistance of Porphyromonas gingivalis in chemotherapeutically cells, we treated EC-9706 cells lines with 3 neo-adjuvant chemotherapeutic drugs, namely, Paclitaxel, Cisplatin, and 5FU. The rationale behind selecting these drugs was that the National Comprehensive Cancer Network 2013 prescribed triple-drug therapy as a treatment against ESCC. In addition, these drugs have different mechanisms of action. Our flowmetry data 
shows that Porphyromonas gingivalis promoted apoptosis resistance against all 3 neoadjuvant drugs in the EC9706 cell line. During the process of apoptosis, phosphatidylserine is expressed over the cell membrane which can be detected by Annexin V dye. Hence, it serves as a marker for early apoptosis. However, in the case of necrosis and late apoptotic phase, the cell membrane integrity is lost. This allows PI dye to stain the nucleus. Hence, the cells that stain positive for both PI and Annexin V are necrotic or late apoptotic cells while the cells which stain only for Annexin V are early apoptotic cells. We also observed that in Paclitaxel group and 5-FU group Porphyromonas gingivalis significantly reduced the drug-induced apoptosis, but it still remained higher than cells that were not treated with a chemotherapy drug. This shows that Porphyromonas gingivalis diminishes the effects of Paclitaxel and 5-FU. However, the same thing cannot be said about Cisplatin. Porphyromonas gingivalis not only reduced the drug-induced apoptosis but brought it down to the level of Cisplatin negative samples. This is an important finding as it suggests Porphyromonas gingivalis not only diminishes but nullifies the effect of Cisplatin. Another interesting result was that Porphyromonas gingivalis did not lower the apoptosis below untreated group. In other words, antiapoptotic activity of Porphyromonas gingivalis was demonstrable only in the presence of chemotherapy drug. This suggests that Porphyromonas gingivalis may be interfering with the drug action.

Next, we wanted to see if this apoptosis resistance is limited only to the EC9706 cell line or can be seen in other ESCC cell lines as well. To achieve this, we infected the following ESCC cell lines with Porphyromonas gingivalis NE3, KYSC30, KYSC70, and EC-9706 and then treated with Paclitaxel. All the cell lines showed similar trends. The 
Porphyromonas gingivalis infected group showed higher apoptosis resistance when compared to the uninfected control group. Also, Porphyromonas gingivalis infected group with Paclitaxel treatment showed significantly higher apoptosis than Paclitaxel negative groups. It shows that Porphyromonas gingivalis promotes apoptosis resistance in multiples ESCC cell lines and though the difference is significant the difference is not overwhelming. Therefore, its biological relevance in patients is questionable. Also, according to the protocol developed by the National Comprehensive Cancer Network 2013 an ESCC patient is supposed to receive all the three drugs simultaneously. It will be interesting to see the effect of Porphyromonas gingivalis in the context of triple-drug therapy.

In our final experiment, we wanted to if Porphyromonas gingivalis to look at the mechanism behind it. We set up the experiment at two different time points of 12 hours and 24 hours. We treated Porphyromonas gingivalis infected EC9706 with Paclitaxel. Caspase 3 plays a central role in the execution-phase and can be activated through both intrinsic as well as the extrinsic mechanism of apoptosis. Further, its cleaved products give an idea about the amount of apoptotic activity. We found that in Porphyromonas gingivalis infected EC9706 cell group lowered the production of Caspase 3. This may suggest a decrease in apoptotic activity. However, since this was performed over a single blot, we cannot it to be conclusive about it. This experiment has to be repeated to establish if there exists a statistical significance. Further, these results need to be supported by knockdown experiments. 
In all the above experiments, we have only compared Esophageal cancer cells. However, normal esophageal cells can be added to these experiments. P.gingivalis have been shown to cause similar effects in human immortalized gingival epithelial cells (HIGECs). We speculate that due to the similar nature of esophageal epithelium P.gingivalis might have similar effects on normal esophageal cells (Geng et al., 2017). 


\section{CONCLUSION}

Esophageal squamous cell carcinoma is highly debilitating and lethal disease. Almost $80 \%$ of its patients die within 5 years of their diagnosis. Studies have shown that Porphyromonas gingivalis further deteriorates the condition of these patients. This study shows how Porphyromonas gingivalis may be causing these effects and suggests that by improving oral hygiene and decreasing Porphyromonas gingivalis load in ESCC patients can help to increase patient's survival.

With further investigation and understanding the molecular mechanism by which Porphyromonas gingivalis exerts these changes, we will be able to develop targeted processes or drugs to inhibit the harmful effects of Porphyromonas gingivalis. Porphyromonas gingivalis specific antibiotics use as an adjunct to chemotherapy can be an interesting proposal. 


\section{REFERENCES}

Aas, J. A., Paster, B. J., Stokes, L. N., Olsen, I., \& Dewhirst, F. E. (2005). Defining the Normal Bacterial Flora of the Oral Cavity. Journal of Clinical Microbiology, 43(11), 5721-5732. https://doi.org/10.1128/JCM.43.11.5721-5732.2005

Ahn, J., Segers, S., \& Hayes, R. B. (2012). Periodontal disease, Porphyromonas gingivalis serum antibody levels and orodigestive cancer mortality. Carcinogenesis, 33(5), 1055-1058. https://doi.org/10.1093/carcin/bgs1 12

Amano, A., Nakagawa, I., Okahashi, N., \& Hamada, N. (2004). Variations of Porphyromonas gingivalis fimbriae in relation to microbial pathogenesis. Journal of Periodontal Research, 39(2), 136-142. https://doi.org/10.1111/j.16000765.2004.00719.x

Arnold, M., Soerjomataram, I., Ferlay, J., \& Forman, D. (2015). Global incidence of oesophageal cancer by histological subtype in 2012. Gut, 64(3), 381-387. https://doi.org/10.1136/gutjnl-2014-308124 
Ashkenazi, A., \& Dixit, V. M. (1998). Death Receptors: Signaling and Modulation. Science, 281(5381), 1305-1308. https://doi.org/10.1126/science.281.5381.1305

Atanasova, K. R., \& Yilmaz, Ö. (2014). Looking in the Porphyromonas gingivalis' Cabinet of Curiosities: The Microbium, the Host and Cancer Association. Molecular Oral Microbiology, 29(2), 55-66. https://doi.org/10.1111/omi.12047

Binder Gallimidi, A., Fischman, S., Revach, B., Bulvik, R., Maliutina, A., Rubinstein, A. M., ... Elkin, M. (2015). Periodontal pathogens Porphyromonas gingivalis and Fusobacterium nucleatum promote tumor progression in an oral-specific chemical carcinogenesis model. Oncotarget, 6(26), 22613-22623. https://doi.org/10.18632/oncotarget.4209

Bostanci, N., \& Belibasakis, G. N. (2012). Porphyromonas gingivalis: an invasive and evasive opportunistic oral pathogen. FEMS Microbiology Letters, 333(1), 1-9. https://doi.org/10.1111/j.1574-6968.2012.02579.x

Bray, F., Ren, J.-S., Masuyer, E., \& Ferlay, J. (n.d.). Global estimates of cancer prevalence for 27 sites in the adult population in 2008. International Journal of Cancer, 132(5), 1133-1145. https://doi.org/10.1002/ijc.27711

Brown, L. M., Hoover, R. N., Greenberg, R. S., Schoenberg, J. B., Schwartz, A. G., Swanson, G. M., ... Pottern, L. M. (1994). Are racial differences in squamous cell 
esophageal cancer explained by alcohol and tobacco use? Journal of the National Cancer Institute, 86(17), 1340-1345.

Cell_Biology.pdf. (n.d.). Retrieved from https://www.dojindo.com/Protocol/Cell_Biology.pdf

Chen, X., Winckler, B., Lu, M., Cheng, H., Yuan, Z., Yang, Y., ... Ye, W. (2015). Oral Microbiota and Risk for Esophageal Squamous Cell Carcinoma in a High-Risk Area of China. PLOS ONE, 10(12), e0143603. https://doi.org/10.1371/journal.pone.0143603

Ci, X., Chen, L., \& Ou, X. (2015). [Grape seed proanthocyanidin extracts inhibit lipopolysaccharide of Porphyromonas gingivalis]. Shanghai Kou Qiang Yi Xиe= Shanghai Journal of Stomatology, 24(4), 433-436.

Cook, M. B. (2011). Non-acid reflux: the missing link between gastric atrophy and esophageal squamous cell carcinoma? The American Journal of Gastroenterology, 106(11), 1930-1932. https://doi.org/10.1038/ajg.2011.288

Cugini, C., Klepac-Ceraj, V., Rackaityte, E., Riggs, J. E., \& Davey, M. E. (2013). Porphyromonas gingivalis: keeping the pathos out of the biont. Journal of Oral Microbiology, 5. https://doi.org/10.3402/jom.v5i0.19804 
Darveau, R. P., Belton, C. M., Reife, R. A., \& Lamont, R. J. (1998). Local Chemokine Paralysis, a Novel Pathogenic Mechanism for Porphyromonas gingivalis. Infection and Immunity, 66(4), 1660-1665.

Dasari, S., \& Tchounwou, P. B. (2014). Cisplatin in cancer therapy: molecular mechanisms of action. European Journal of Pharmacology, 0, 364-378. https://doi.org/10.1016/j.ejphar.2014.07.025

de Diego, I., Veillard, F., Sztukowska, M. N., Guevara, T., Potempa, B., Pomowski, A., ... Gomis-Rüth, F. X. (2014). Structure and Mechanism of Cysteine Peptidase Gingipain K (Kgp), a Major Virulence Factor of Porphyromonas gingivalis in Periodontitis. The Journal of Biological Chemistry, 289(46), 32291-32302. https://doi.org/10.1074/jbc.M114.602052

Di Pilato, V., Freschi, G., Ringressi, M. N., Pallecchi, L., Rossolini, G. M., \& Bechi, P. (2016). The esophageal microbiota in health and disease: Esophageal microbiota and disease. Annals of the New York Academy of Sciences, 1381(1), 21-33. https://doi.org/10.1111/nyas.13127

Eke, P. I., Dye, B. A., Wei, L., Thornton-Evans, G. O., \& Genco, R. J. (2012). Prevalence of Periodontitis in Adults in the United States: 2009 and 2010. Journal of Dental Research, 91(10), 914-920. https://doi.org/10.1177/0022034512457373 
Elmore, S. (2007). Apoptosis: A Review of Programmed Cell Death. Toxicologic Pathology, 35(4), 495-516. https://doi.org/10.1080/01926230701320337

Fact Sheets by Cancer. (n.d.). Retrieved May 30, 2018, from http://globocan.iarc.fr/Pages/fact_sheets_cancer.aspx

Fan, X., Alekseyenko, A. V., Wu, J., Peters, B. A., Jacobs, E. J., Gapstur, S. M., ... Ahn, J. (2018). Human oral microbiome and prospective risk for pancreatic cancer: a population-based nested case-control study. Gut, 67(1), 120-127. https://doi.org/10.1136/gutjnl-2016-312580

Ferlay, J., Soerjomataram, I., Ervik, M., Dikshit, R., Eser, S., Mathers, C., ... Bray, F. (2013). Cancer Incidence and Mortality Worldwide. Retrieved from http://globocan.iarc.fr/

Focaccetti, C., Bruno, A., Magnani, E., Bartolini, D., Principi, E., Dallaglio, K., ... Albini, A. (2015). Effects of 5-Fluorouracil on Morphology, Cell Cycle, Proliferation, Apoptosis, Autophagy and ROS Production in Endothelial Cells and Cardiomyocytes. PLOS ONE, 10(2), e0115686. https://doi.org/10.1371/journal.pone.0115686

Gao, S., Li, S., Ma, Z., Liang, S., Shan, T., Zhang, M., ... Feng, X. (2016). Presence of Porphyromonas gingivalis in esophagus and its association with the 
clinicopathological characteristics and survival in patients with esophageal cancer. Infectious Agents and Cancer, 11, 3. https://doi.org/10.1186/s13027-0160049-x

Geng, F., Liu, J., Guo, Y., Li, C., Wang, H., Wang, H., ... Pan, Y. (2017). Persistent Exposure to Porphyromonas gingivalis Promotes Proliferative and Invasion Capabilities, and Tumorigenic Properties of Human Immortalized Oral Epithelial Cells. Frontiers in Cellular and Infection Microbiology, 7, 57. https://doi.org/10.3389/fcimb.2017.00057

Gokyu, M., Kobayashi, H., Nanbara, H., Sudo, T., Ikeda, Y., Suda, T., \& Izumi, Y. (2014). Thrombospondin-1 Production Is Enhanced by Porphyromonas gingivalis Lipopolysaccharide in THP-1 Cells. PLoS ONE, 9(12). https://doi.org/10.1371/journal.pone.0115107

Groeger, S., Domann, E., Gonzales, J. R., Chakraborty, T., \& Meyle, J. (2011). B7-H1 and B7-DC receptors of oral squamous carcinoma cells are upregulated by Porphyromonas gingivalis. Immunobiology, 216(12), 1302-1310. https://doi.org/10.1016/j.imbio.2011.05.005

Ha, N. H., Park, D. G., Woo, B. H., Kim, D. J., Choi, J. I., Park, B. S., .. Park, H. R. (2016). Porphyromonas gingivalis increases the invasiveness of oral cancer cells 
by upregulating IL-8 and MMPs. Cytokine, 86, 64-72.

https://doi.org/10.1016/j.cyto.2016.07.013

Ha, N. H., Woo, B. H., Kim, D. J., Ha, E. S., Choi, J. I., Kim, S. J., .. Park, H. R. (2015). Prolonged and repetitive exposure to Porphyromonas gingivalis increases aggressiveness of oral cancer cells by promoting acquisition of cancer stem cell properties. Tumour Biology: The Journal of the International Society for Oncodevelopmental Biology and Medicine, 36(12), 9947-9960. https://doi.org/10.1007/s13277-015-3764-9

Herath, T. D. K., Darveau, R. P., Seneviratne, C. J., Wang, C.-Y., Wang, Y., \& Jin, L. (2016). Heterogeneous Porphyromonas gingivalis LPS modulates immunoinflammatory response, antioxidant defense and cytoskeletal dynamics in human gingival fibroblasts. Scientific Reports, 6, 29829. https://doi.org/10.1038/srep29829

Hoppe, T., Kraus, D., Novak, N., Probstmeier, R., Frentzen, M., Wenghoefer, M., ... Winter, J. (2016). Oral pathogens change proliferation properties of oral tumor cells by affecting gene expression of human defensins. Tumour Biology: The Journal of the International Society for Oncodevelopmental Biology and Medicine, 37(10), 13789-13798. https://doi.org/10.1007/s13277-016-5281-x 
How, K. Y., Song, K. P., \& Chan, K. G. (2016). Porphyromonas gingivalis: An Overview of Periodontopathic Pathogen below the Gum Line. Frontiers in Microbiology, 7. https://doi.org/10.3389/fmicb.2016.00053

Hu, J., Kent, P., Lennon, J. M., \& Logan, L. K. (2015). Acute necrotising ulcerative gingivitis in an immunocompromised young adult. BMJ Case Reports, 2015. https://doi.org/10.1136/bcr-2015-211092

Hujoel, P., Zina, L. G., Cunha-Cruz, J., \& Lopez, R. (2012). Historical perspectives on theories of periodontal disease etiology. Periodontology 2000, 58(1), 153-160. https://doi.org/10.1111/j.1600-0757.2011.00423.x

Hwang, H. C., \& Clurman, B. E. (2005). Cyclin E in normal and neoplastic cell cycles. Oncogene, 24(17), 2776-2786. https://doi.org/10.1038/sj.onc.1208613

Inaba, H., Sugita, H., Kuboniwa, M., Iwai, S., Hamada, M., Noda, T., ... Amano, A. (2014). Porphyromonas gingivalis promotes invasion of oral squamous cell carcinoma through induction of proMMP9 and its activation. Cellular Microbiology, 16(1), 131-145. https://doi.org/10.1111/cmi.12211

Jain, Shilpa, \& Dhingra, S. (2017). Pathology of esophageal cancer and Barrett's esophagus. Annals of Cardiothoracic Surgery, 6(2), 99-109. https://doi.org/10.21037/acs.2017.03.06 
Jain, Sumita, \& Darveau, R. P. (2010). Contribution of Porphyromonas gingivalis lipopolysachharide to periodontitis. Periodontology 2000, 54(1), 53-70. https://doi.org/10.1111/j.1600-0757.2009.00333.x

Jian, C.-X., Li, M.-Z., Zheng, W.-Y., He, Y., Ren, Y., Wu, Z.-M., .. Li, C.-J. (2015). Tormentic acid inhibits LPS-induced inflammatory response in human gingival fibroblasts via inhibition of TLR4-mediated NF- $\mathrm{B}$ and MAPK signalling pathway. Archives of Oral Biology, 60(9), 1327-1332. https://doi.org/10.1016/j.archoralbio.2015.05.005

Kassebaum, N. J., Smith, A. G. C., Bernabé, E., Fleming, T. D., Reynolds, A. E., Vos, T., ... Marcenes, W. (2017). Global, Regional, and National Prevalence, Incidence, and Disability-Adjusted Life Years for Oral Conditions for 195 Countries, 19902015: A Systematic Analysis for the Global Burden of Diseases, Injuries, and Risk Factors. Journal of Dental Research, 96(4), 380-387. https://doi.org/10.1177/0022034517693566

Katz, J., Onate, M. D., Pauley, K. M., Bhattacharyya, I., \& Cha, S. (2011). Presence of Porphyromonas gingivalis in gingival squamous cell carcinoma. International Journal of Oral Science, 3(4), 209. https://doi.org/10.4248/IJOS11075

Kerr, J. F. R., Wyllie, A. H., \& Currie, A. R. (1972). Apoptosis: A Basic Biological Phenomenon with Wideranging Implications in Tissue Kinetics. British Journal of Cancer, 26(4), 239-257. https://doi.org/10.1038/bjc.1972.33 
Khanna, C., Rosenberg, M., \& Vail, D. M. (2015). A Review of Paclitaxel and Novel Formulations Including Those Suitable for Use in Dogs. Journal of Veterinary Internal Medicine, 29(4), 1006-1012. https://doi.org/10.1111/jvim.12596

Kuo, B., \& Urma, D. (2006). Esophagus - anatomy and development. GI Motility Online. https://doi.org/10.1038/gimo6

Laine, M. L., Appelmelk, B. J., \& van Winkelhoff, A. J. (1997). Prevalence and distribution of six capsular serotypes of Porphyromonas gingivalis in periodontitis patients. Journal of Dental Research, 76(12), 1840-1844. https://doi.org/10.1177/00220345970760120601

Lamont, R. J., \& Hajishengallis, G. (2015). Polymicrobial synergy and dysbiosis in inflammatory disease. Trends in Molecular Medicine, 21(3), 172-183. https://doi.org/10.1016/j.molmed.2014.11.004

Liang, H., Fan, J.-H., \& Qiao, Y.-L. (2017). Epidemiology, etiology, and prevention of esophageal squamous cell carcinoma in China. Cancer Biology \& Medicine, 14(1), 33-41. https://doi.org/10.20892/j.issn.2095-3941.2016.0093

Lin, F.-Y., Huang, C.-Y., Lu, H.-Y., Shih, C.-M., Tsao, N.-W., Shyue, S.-K., ... Lin, S.-J. (2015). The GroEL protein of Porphyromonas gingivalis accelerates tumor 
growth by enhancing endothelial progenitor cell function and neovascularization. Molecular Oral Microbiology, 30(3), 198-216. https://doi.org/10.1111/omi.12083

Löe, H. (1993). Periodontal diseases: a brief historical perspective. Periodontology 2000, 2(1), 7-12. https://doi.org/10.1111/j.1600-0757.1993.tb00215.x

Majno, G., \& Joris, I. (1995). Apoptosis, Oncosis, and Necrosis, 146(1), 13.

Maleki, I., Shekarriz, R., Nosrati, A., \& Orang, E. (2015). Simultaneous Esophageal Squamous Cell Carcinoma and Adenocarcinoma: A Case Report. Middle East Journal of Digestive Diseases, 4.

Malumbres, M. (2014). Cyclin-dependent kinases. Genome Biology, 15(6), 122. https://doi.org/10.1186/gb4184

Marcenes, W., Kassebaum, N. J., Bernabé, E., Flaxman, A., Naghavi, M., Lopez, A., \& Murray, C. J. L. (2013). Global Burden of Oral Conditions in 1990-2010. Journal of Dental Research, 92(7), 592-597. https://doi.org/10.1177/0022034513490168

Marsh, P. D. (1994). Microbial ecology of dental plaque and its significance in health and disease. Advances in Dental Research, 8(2), 263-271. https://doi.org/10.1177/08959374940080022001 
Michaud, D. S., Izard, J., Wilhelm-Benartzi, C. S., You, D.-H., Grote, V. A., Tjønneland, A., ... Riboli, E. (2013). Plasma antibodies to oral bacteria and risk of pancreatic cancer in a large European prospective cohort study. Gut, 62(12). https://doi.org/10.1136/gutjnl-2012-303006

Mima, K., Nishihara, R., Qian, Z. R., Cao, Y., Sukawa, Y., Nowak, J. A., ... Ogino, S. (2016). Fusobacterium nucleatum in colorectal carcinoma tissue and patient prognosis. Gut, 65(12), 1973-1980. https://doi.org/10.1136/gutjnl-2015-310101

Miranda-Rius, J., Brunet-Llobet, L., \& Lahor-Soler, E. (2018). The Periodontium as a Potential Cause of Orofacial Pain: A Comprehensive Review. The Open Dentistry Journal, 12, 520-528. https://doi.org/10.2174/1874210601812010520

Mysak, J., Podzimek, S., Sommerova, P., Lyuya-Mi, Y., Bartova, J., Janatova, T., ... Duskova, J. (2014). Porphyromonas gingivalis: Major Periodontopathic Pathogen Overview. Journal of Immunology Research, 2014. https://doi.org/10.1155/2014/476068

Napier, K. J., Scheerer, M., \& Misra, S. (2014). Esophageal cancer: A Review of epidemiology, pathogenesis, staging workup and treatment modalities. World Journal of Gastrointestinal Oncology, 6(5), 112-120. https://doi.org/10.4251/wjgo.v6.i5.112 
Nisha. (n.d.). Periodontal disease - Historical and contemporary hypothesis: A review. Retrieved November 7, 2018, from http://www.srmjrds.in/article.asp?issn=0976433X; year $=2017 ;$ volume $=8 ;$ issue $=3 ;$ spage $=121 ;$ epage $=125 ;$ aulast $=$ Nisha

Park, J.-H., Yoon, H.-E., Jeon, D.-I., Ahn, S.-G., \& Yoon, J.-H. (2010). Activation of TLR2 and TLR5 did not affect tumor progression of an oral squamous cell carcinoma, YD-10B cells. Journal of Oral Pathology \& Medicine: Official Publication of the International Association of Oral Pathologists and the American Academy of Oral Pathology, 39(10), 781-785. https://doi.org/10.1111/j.1600-0714.2010.00900.x

PERIODONTIUM - AAP Connect. (n.d.). Retrieved June 26, 2018, from https://members.perio.org/libraries/glossary/entry?GlossaryKey=3a1fa720-57fc48cd-93d9-06db26ff48c1\&tab=groupdetails

Peters, B. A., Wu, J., Pei, Z., Yang, L., Purdue, M. P., Freedman, N. D., ... Ahn, J. (2017). Oral Microbiome Composition Reflects Prospective Risk for Esophageal Cancers. Cancer Research, 77(23), 6777-6787. https://doi.org/10.1158/00085472.CAN-17-1296

Pickens, A., \& Orringer, M. B. (2003). Geographical distribution and racial disparity in esophageal cancer. The Annals of Thoracic Surgery, 76(4), S1367-S1369. https://doi.org/10.1016/S0003-4975(03)01202-5 
Plaza, K., Kalinska, M., Bochenska, O., Meyer-Hoffert, U., Wu, Z., Fischer, J., ... Kantyka, T. (2016). Gingipains of Porphyromonas gingivalis Affect the Stability and Function of Serine Protease Inhibitor of Kazal-type 6 (SPINK6), a Tissue Inhibitor of Human Kallikreins. The Journal of Biological Chemistry, 291(36), 18753-18764. https://doi.org/10.1074/jbc.M116.722942

Shang, F.-M., \& Liu, H.-L. (2018). Fusobacterium nucleatum and colorectal cancer: A review. World Journal of Gastrointestinal Oncology, 10(3), 71-81. https://doi.org/10.4251/wjgo.v10.i3.71

Shimada, Y., Imamura, M., Wagata, T., Yamaguchi, N., \& Tobe, T. (1992). Characterization of 21 newly established esophageal cancer cell lines. Cancer, 69(2), 277-284. https://doi.org/10.1002/1097-0142(19920115)69:2<277::AIDCNCR2820690202>3.0.CO;2-C

Singh, A., Wyant, T., Anaya-Bergman, C., Aduse-Opoku, J., Brunner, J., Laine, M. L., ... Lewis, J. P. (2011). The Capsule of Porphyromonas gingivalis Leads to a Reduction in the Host Inflammatory Response, Evasion of Phagocytosis, and Increase in Virulence $\nabla$. Infection and Immunity, 79(11), 4533-4542. https://doi.org/10.1128/IAI.05016-11 
Siu, K. T., Rosner, M. R., \& Minella, A. C. (2012). An integrated view of cyclin E function and regulation. Cell Cycle, 11(1), 57-64. https://doi.org/10.4161/cc.11.1.18775

Socransky, S. S., Haffajee, A. D., Cugini, M. A., Smith, C., \& Kent, R. L. (1998). Microbial complexes in subgingival plaque. Journal of Clinical Periodontology, 25(2), 134-144.

Srour, M. L., Marck, K., \& Baratti-Mayer, D. (2017). Noma: Overview of a Neglected Disease and Human Rights Violation. The American Journal of Tropical Medicine and Hygiene, 96(2), 268-274. https://doi.org/10.4269/ajtmh.16-0718

Tezal, M., Sullivan, M. A., Hyland, A., Marshall, J. R., Stoler, D., Reid, M. E., ... Scannapieco, F. A. (2009). Chronic Periodontitis and the Incidence of Head and Neck Squamous Cell Carcinoma. Cancer Epidemiology and Prevention Biomarkers, 18(9), 2406-2412. https://doi.org/10.1158/1055-9965.EPI-09-0334

Theilade, E. (1986). The non-specific theory in microbial etiology of inflammatory periodontal diseases. Journal of Clinical Periodontology, 13(10), 905-911.

Tonetti, M. S., Greenwell, H., \& Kornman, K. S. (2018). Staging and grading of periodontitis: Framework and proposal of a new classification and case definition. Journal of Periodontology, 89 Suppl 1, S159-S172.

https://doi.org/10.1002/JPER.18-0006 
Yazaki, E., \& Sifrim, D. (2012). Anatomy and physiology of the esophageal body: Anatomy and physiology of the esophagus. Diseases of the Esophagus, 25(4), 292-298. https://doi.org/10.1111/j.1442-2050.2011.01180.x

Zeng, F.-M., Zeng, F.-M., Xie, Y.-M., Xie, Y.-M., Liao, L.-D., Liao, L.-D., ... Li, E.-M. (2016). Biological characterization of three immortalized esophageal epithelial cell lines. Molecular Medicine Reports, 14(5), 4802-4810. https://doi.org/10.3892/mmr.2016.5813

Zhang, W., Ju, J., Rigney, T., \& Tribble, G. D. (2011). Fimbriae of Porphyromonas gingivalis are important for initial invasion of osteoblasts, but not for inhibition of their differentiation and mineralization. Journal of Periodontology, 82(6), 909916. https://doi.org/10.1902/jop.2010.100501

Zhang, Y. (2013). Epidemiology of esophageal cancer. World Journal of Gastroenterology: WJG, 19(34), 5598-5606. https://doi.org/10.3748/wjg.v19.i34.5598

Zhou, Y., Sztukowska, M., Wang, Q., Inaba, H., Potempa, J., Scott, D. A., ... Lamont, R. J. (2015). Noncanonical activation of $\beta$-catenin by Porphyromonas gingivalis. Infection and Immunity, 83(8), 3195-3203. https://doi.org/10.1128/IAI.00302-15 


\section{CURRICULUM VITAE}

Name: Muddasir Mohammed

Address: 502 S. Preston, Room No.263C, School of Dentistry, University of Louisville 40202.

\section{Education}

Aug 2007-April 2012

Jan 2015- Apr 2016

Aug 2016- Nov 2018

Nov 2012- Nov 2014

Sep 2015- Apr 2016

May 2017- Aug 2017

Dec 2016-ongoing

\section{Work Experience}

\section{Bachelor of Dental Surgery}

NTR University of Health Sciences

Master of Business Administration

University of Findlay

Master of Science in Oral Biology

University of Louisville

\section{Dentist}

Sudantha Dental Clinic, Andhra Pradesh, India

Research Assistant, University of Findlay, Findlay, OH Summer Research Fellow University of Louisville, KY. Student Assistant in Dental Clinical Support University of Louisville, Louisville, KY. 
May 2018-Aug 2018

Publication

Presentations

Aug 05, 2017

Mar 22,2018

2017-18
Summer Research Fellow, University of Louisville,

Louisville, KY.

\section{Under review}

Shegan Gao, Yiwen Liu, Xiaoxiab Duan, Muddasir Mohammed, Fuyou Zhou, Yi Jun Qui, Xiang Yaun, Shuoguo Li, Zhikun Ma, Lanhai Lu, Juling Ren, Lan Chen, Zhen Gu, David Scott, Richard Lamont, Huizhi Wang, (2018), 'Porphyromonas gingivalis infection alters esophageal microbiome and aggravates esophageal cancer through affecting cell viability'. (Under review: Nature Medicine; Manuscript on request

'Influence of Porphyromonas gingivalis on the apoptosis Esophageal Carcinoma Cells', Research! Louisville, University of Louisville, Louisville, KY.

Influence of Porphyromonas gingivalis on the apoptosis Esophageal Carcinoma Cells', 47th AADR and CADR Annual Meeting and Exhibition, Fort Lauderdale, Florida, USA, 2018.

PROFESSIONAL AFFILIATIONS/ MEMBERSHIP

a. American Society for Forensic Odontology 

b. American Student Dental Association
c. American Association for Dental Research
d. National Student Research Group
e. Indian Dental Association
f. Andhra Pradesh State Dental Council

\section{AWARDS \& HONORS}

a) Runner up at Research! Louisville 2017, School of Dentistry, University of Louisville, Louisville, Kentucky, 40202.

b) Served as a Public Relations Officer for the Student Research Group, School of Dentistry, University of Louisville, Kentucky, 40202. 